Björn Opfer-Klinger

\title{
Albanien als Krisen- und Kriegsgebiet 1908-1921
}

Die Region, die wir heute als albanisches Siedlungsgebiet kennen, also in erster Linie das Staatsgebiet von Albanien, das Kosovo und das westliche Mazedonien, gehörte zu Beginn des 20. Jahrhunderts zu den Brennpunkten Europas. Die »Albanische Frage« sollte 1912-1914 wesentlich zur Destabilisierung des Balkans und der internationalen Politik bzw. zur verheerenden Eskalation zwischen den Großmächten im Sommer 1914 beitragen. Zur Jahrhundertwende zählte die Region noch zu den stabilsten europäischen Territorien des immer mehr kriselnden Osmanischen Reiches. Noch stand die Mehrheit der dortigen albanischsprachigen Bevölkerung hinter dem Sultan und Kalifen in Istanbul. Dennoch rivalisierten dort immer aggressiver verschiedene Mächte um Einfluss. Dazu zählten die regionalen Anrainer Montenegro, Serbien und Griechenland, aber auch die Großmächte Italien und Österreich-Ungarn. Die Motive waren dabei sehr unterschiedlich. In Montenegro war es der regierende Fürst bzw. seit 1910 als König herrschende Nikola I., der von der Schwäche des Osmanischen Reiches profitieren und sein Land weiter ausdehnen wollte. In Serbien wurde das Amselfeld, Teil des Kosovo, als historisch urserbisches Gebiet angesehen. Darüber hinaus wurde spätestens seit dem Zollkrieg mit Österreich-Ungarn, dem sogenannten »Schweinekrieg « (1906-1908) der Ruf nach einem eigenen serbischen Exporthafen laut, der sich am ehesten an der albanischen Adriaküste zu verwirklichen schien. Dies jedoch wurde von der k.u.k. Regierung in Wien, die im serbischen Nationalismus zunehmend eine Bedrohung für den habsburgischen Vielvölkerstaat sah, kategorisch abgelehnt. Ähnlich verhielt es sich mit Griechenland, dessen nationalistischen Kreise die Region des Epirus als zu »befreiendes« griechisches Gebiet ansahen. Dieses Ansinnen wurde wiederum als Bedrohung des erst seit Kurzem zur imperialen Großmacht aufgestiegenen italienischen Staates wahrgenommen. Italien wollte selbst seinen Einfluss auf dem südwestlichen Balkan ausdehnen und musste daher zwangsläufig Griechenland als störenden Rivalen ansehen. Angesichts der gespannten Beziehungen zwischen Italien und Österreich-Ungarn gewann die Rivalität über den dominierenden Einfluss an der albanischen Küste eine wachsende Sprengkraft. In Wien war man sich nur zu sehr bewusst, dass eine italienische Dominanz zwischen den Häfen Vlora und Durrës unweigerlich die Kontrolle Italiens über die Straße von Otranto und damit über die ganze Adria zur Folge gehabt hätte. So bemühten sich viele Akteure darum, ihren Einfluss in dieser osmanischen Randregion auszubauen. Zwangsläufig musste sich dies auch auf die lokale Bevölkerung auswirken.

\section{Die Entwicklung der albanischen Nationalbewegung}

In einer langen, alles andere als stringenten Entwicklung bildete sich im 19. Jahrhundert eine kleine albanische Nationalbewegung heraus. Dies geschah durchaus parallel zum bulgarischen oder serbischen Nationalismus, doch entstanden für 
den albanischen Nationalismus erst Anfang des 20. Jahrhunderts die nötigen Rahmenbedingungen, welche die Gründung eines albanischen Staates ermöglichten. Diese Gründungsphase wurde maßgeblich geprägt durch die Auswirkungen der jungtürkischen Revolution im Jahr 1908, den daraufhin folgenden militärischen Konflikten sowie den Auswirkungen des Ersten Weltkrieges. Verbunden damit ist die Frage, welche gesellschaftliche Bedeutung die schwindende Integrationskraft des osmanischen Sultans und Kalifen im Zuge der jungtürkischen Revolution für die mehrheitlich muslimischen Albaner vor dem Hintergrund der albanischen Staatswerdung besaß.

In einem weiteren Schritt gilt es zu untersuchen, welche politische Bedeutung die überwiegend albanisch dominierten Territorien auf dem südwestlichen Balkan in einer Zeit gewannen, in der einerseits imperialistische Rivalitäten der Großmächte sich mehr und mehr von den Kolonialreichen zurück nach Europa verlagerten und andererseits die im 19. Jahrhundert entstandenen Balkanstaaten sich anschickten, ihrerseits eine expansive Machtpolitik zu betreiben. Die dabei entstehenden Balkankriege 1912/13 und der Erste Weltkrieg brachten nicht nur einen »kleinalbanischen « Staat hervor, sondern prägten diesen nachhaltig. Manche Entscheidungen und Prozesse wirken bis in unsere Gegenwart nach.

Die albanischsprachige Bevölkerung prägte besonders die osmanischen Vilâyete Kosovo, Manastir und Shkodra, teilweise auch Saloniki und Ioannina. Dabei handelte es sich zu Beginn des 20. Jahrhunderts um eine äußerst heterogene Gruppe, die weit davon entfernt war, sich als kollektive Nation zu begreifen. Stattdessen überwogen religiöse, soziale und kleinregionale Familien- und Verwandtschaftsbeziehungen als zentrale Identitätsmuster ${ }^{1}$. Es bestand also eine Situation, die sich wenig von der anderer Balkannationen unterschied, bevor diese eine eigene Staatlichkeit durchsetzen konnten. Die sozialen Unterschiede innerhalb der albanischsprachigen Bevölkerung waren beträchtlich. Der überwiegende Teil der Bevölkerung lebte von der Landwirtschaft. Nur drei Prozent der Familien verfügten über ein Viertel des gesamten landwirtschaftlichen Kulturlandes mit durchschnittlich 19 Hektar. Sieben Familien besaßen Landgüter mit mehr als 2000 Hektar $^{2}$. Im äußersten Norden basierten gesellschaftliche Strukturen nicht selten noch auf traditionellen Stammesverbänden, im Kosovo hingegen auf großfamiliären Clanverbänden. Besonders in den Handels- und Verwaltungszentren an der Küste und im Süden hatte sich hingegen eine bürgerliche Schicht etabliert.

Religiös war die albanischsprachige Bevölkerung gespalten. Im Norden und in einigen Gemeinden des Kosovo überwog der Katholizismus. Im Süden dominierte die griechisch-orthodoxe Konfession. Ansonsten dominierte klar der Islam, auch wenn hier starke Unterschiede zwischen der mehrheitlich sunnitischen Bevölkerung und der kleineren Gruppe von Anhängern des Bektaşi-Sufismus und ande-

1 Eva Anne Frantz, Religiös geprägte Lebenswelten im spätosmanischen Kosovo. In: Religion und Kultur im albanischsprachigen Südosteuropa. Hrsg. von Oliver Jens Schmitt, Frankfurt a.M. 2010 (= Pro Oriente: Schriftenreihe der Kommission für Südosteuropäische Geschichte), S. 127-150, hier S. 127.

2 Christoph Baumann, Die albanische »Transformationsregion « Gjirokastra. Strukturwandel im 20. Jahrhundert, räumliche Trends und Handlungsmuster im ruralen Raum. Bamberg 2008 (= Bamberger geographische Schriften, 43), S. 43. 
rer Derwischorden bestanden ${ }^{3}$. Entsprechend groß war der Einfluss der muslimischen Geistlichkeit ${ }^{4}$. Phasenweise hatte der Beitritt zum Islam eine Schutzfunktion gegenüber den zahlenmäßig starken orthodoxen Slawen und Griechen gehabt und so einen wichtigen identitätsstiftenden Faktor eingenommen ${ }^{5}$. Dies galt nicht zuletzt für die seit der Orientkrise 1875-1878 steigende Zahl von muslimischen Flüchtlingen und Vertriebenen aus Bosnien, der Herzegowina und Südserbien, die sich im Kosovo und Westmakedonien niedergelassen hatten. Gerade diese sollten besonders empfänglich sein für neue Identifikationsmuster wie den albanischen Nationalismus in Abgrenzung zu den slawisch-orthodoxen Nachbarn. Die Albanologin Eva Anne Frantz warnt allerdings davor, die Bedeutung der Religiosität für die albanische Identitätsbildung überzubewerten, da die Quellenlage diesbezüglich schwierig sei ${ }^{6}$. Fest steht, dass die Entwicklung des albanischen Nationalismus anders als die des griechischen oder bulgarischen Nationalismus nicht genuin religiös geprägt war. So empfanden sich die muslimischen Eliten noch bis in die 1930er Jahre als gesellschaftlich führende Gruppe, die der orthodoxen Minderheit mit großer Skepsis begegnete ${ }^{7}$. Auch am Vorabend der Balkankriege galt die Loyalität der Albaner in erster Linie der Dorf-, Familien- oder Stammesgemeinschaft bzw. dem Staat in Gestalt des Sultans und Kalifen und nicht einer übergeordneten nationalen Gemeinschaft. Ein äußerst wichtiger verbindender Faktor war allerdings früh die gemeinsame Sprache, auch wenn zunächst noch keine kodifizierte albanische Schriftsprache existierte . $^{8}$

Die ersten Vertreter einer albanischen Nationalbewegung waren albanisch-muslimische Feudalherren, die als Verwaltungsbeamte in Kontakt mit nationalistischen Ideologien Westeuropas gekommen waren oder selbst eine westlich geprägte Ausbildung genossen hatten. Eine andere frühe Keimzelle bildeten Kaufleute oder Handwerker aus dem orthodoxen Süden mit Kontakten zu den wachsenden albanischen Auslandsgemeinden in Paris, Bukarest oder Alexandria ${ }^{9}$. Zu einer wichtigen Wegmarke sollte allerdings die Orientkrise 1875-1878 werden. In den Jahren zuvor hatten sich die sozioökonomischen Probleme in Südosteuropa dramatisch zugespitzt. Aufstände nahmen zu und lieferten schließlich Russland 1877 den Vorwand, dem Osmanischen Reich den Krieg zu erklären. Nunmehr offenbarte sich die Schwäche der osmanischen Herrschaft in verheerender Weise. Russland zwang im Frühjahr 1878 dem osmanischen Sultan die Abtretung eines großen Teils seiner

3 Hanns Christian Löhr, Die Gründung Albaniens. Wilhelm zu Wied und die Balkandiplomatie der Großmächte 1912-1914, Frankfurt a.M. 2010, S. 19 f., und Frantz, Religiös geprägte Lebenswelten im spätosmanischen Kosovo (wie Anm. 1), S. 129 f.

4 Konrad Clewing, Religion und Nation bei den Albanern. Von Anspruch und Wirkungsmacht eines Religionen übergreifenden Nationenkonzepts. In: Politische Kultur in Südosteuropa. Identitäten, Loyalitäten, Solidaritäten. Hrsg. von Alois Mosser, Frankfurt a.M. 2006, S. 147-181, hier S. 159.

5 Ger Duijzings, Qerbelaja e Naim Frashërit: Feja dhe Politika ne Shiqipëria. In: Roli i miteve në historinë e Shqipërise, Përjekja 15-16, Tirana 1999, S. 44-57, hier S. 45.

6 Frantz, Religiös geprägte Lebenswelten im spätosmanischen Kosovo (wie Anm. 1), S. 139.

7 Oliver Jens Schmitt, Die Albaner. Eine Geschichte zwischen Orient und Okzident, München 2012, S. 120 f.

8 Robert C. Austin, Greater Albania. The Albanian State and the Question of Kosovo, 1912-2011. In: Ideologies and National Identities. The Case of Twentieth-Century Southeastern Europe. Ed. by John R. Lampe and Mark Mazower, New York 2004, S. 235-253, hier S. 239, und Clewing, Religion und Nation bei den Albanern (wie Anm. 4), S. 152.

9 Schmitt, Die Albaner (wie Anm. 7), S. 144. 
europäischen Territorien - und damit auch der albanischen Siedlungsgebiete - auf. Zwar wurde der Frieden von San Stefano letztlich nicht umgesetzt - trotzdem zeigte sich auf dem nachfolgenden Berliner Kongress 1878, dass die osmanische Zentralgewalt nicht mehr in der Lage war, die Interessen ihrer Untertanen zu verteidigen. Noch vor Beginn des Berliner Kongresses bildete sich eine Sammelbewegung albanischer Intellektueller und Vertreter einflussreicher muslimisch-albanischer Großgrundbesitzer in der sogenannten Liga von Prizren ${ }^{10}$. Bis Anfang des 20. Jahrhunderts breitete sich langsam unter Teilen der gesellschaftlichen Eliten die Vorstellung von einer albanischen Nation aus. Treibende Kraft war meist der Abwehrmechanismus gegenüber der griechischen oder serbischen Bedrohung von außen als wichtigstes verbindendes Element.

Allerdings musste die albanische Nationalbewegung nicht nur zwischen den politischen Polen Istanbul, Belgrad, Cetinje und Athen agieren, sondern sich auch gegen die Vereinnahmung durch die europäischen Großmächte behaupten. Dabei begannen die Schwierigkeiten bereits damit, dass die albanische Nationalbewegung in der europäischen Öffentlichkeit kaum als solche wahrgenommen, sondern eher als muslimische Bewegung angesehen wurde ${ }^{11}$. Besonders Österreich-Ungarn und Italien bemühten sich um Einfluss auf die katholischen Albaner im äußersten Norden. Wie bereits eingangs erwähnt, war beiden bewusst, dass derjenige, der die albanische Adriaküste kontrollierte, auch den Zugang vom Mittelmeer in die Adria beherrschen konnte. Es einte sie jedoch, dass sie eine Ausdehnung Griechenlands und Serbiens in dieser Region ablehnten ${ }^{12}$.

\section{Die jungtürkische Revolution und ihre Folgen}

Die Ereignisse gewannen an Dynamik, als 1908 die Reformbewegung der Jungtürken im Osmanischen Reich die Macht übernahm ${ }^{13}$. Auch viele Angehörige der albanischen Eliten sympathisierten mit den jungtürkischen Reformern. Ein beredtes Beispiel stellt der kosovarische Politiker Hasan Bey Prishtina dar. Dieser sah zunächst in den jungtürkischen Reformideen die Chance für eine Stabilisierung des Reichs. Nach dem Sieg der Revolution ließ er sich als Abgeordneter ins Parlament wählen, wo er wiederum begann, engen Kontakt zu südalbanischen Politikern aufzubauen. Einen ähnlichen Weg beschritt der aus Mittelalbanien stammende Groß-

Michael Schmidt-Neke, Entstehung und Ausbau der Königsdiktatur in Albanien (1912-1939).

Regierungsbildungen, Herrschaftsweise und Machteliten in einem jungen Balkanstaat, München 1987 (= Südosteuropäische Arbeiten, 84), S. 20.

11 Clewing, Religion und Nation bei den Albanern (wie Anm. 4), S. 168.

12 Hans Dieter Schanderl, Die Albanienpolitik Österreich-Ungarns und Italiens 1877-1908, Wiesbaden 1971 (= Albanische Forschungen, 9), S. 57.

13 Zum Thema Jungtürken, Jungtürkische Revolution und jungtürkische Herrschaft siehe u.a.: Mehmet Hacısalihoğlu, Die Jungtürken und die Mazedonische Frage (1890-1918), München 2003 (= Südosteuropäische Arbeiten, 116); Masami Arai, Turkish nationalism in the Young Turk era, Leiden 1997 (= Social, economic and political studies of the Middle East, 43); Mehmet Naim Turfan, Rise of the Young Turks: Politics, the Military and Ottoman Collapse, London 2000; Mehmed Şükrü Hanioğlu, Preparation for a Revolution. The Young Turks, 1902-1908, Oxford 2001, und Erik J. Zürcher, The Young Turk Legacy and Nation Building. From the Ottoman Empire to Atatürk's Turkey, London 2010. 
grundbesitzer Esat Pascha Toptani. Auch er ließ sich nach der Revolution ins Parlament wählen, schwankte allerdings zwischen der Unterstützung der albanischen Nationalbewegung und der Vertretung primär feudaler Interessen.

Tatsächlich schien es, als würde die albanische Nationalbewegung unter der jungtürkischen Herrschaft viele ihrer Ziele umsetzen können. Die Zustimmung währte allerdings nur kurz. Die Vorstellungen eines multiethnischen Osmanismus und einer eventuell stärker föderativen Staatsstruktur gerieten bald ins Abseits. Stattdessen gewann innerhalb der jungtürkischen Bewegung die radikale Fraktion an Gewicht. Diese strebte nach einem modernen, säkularen und zentralistischen Staat. Eine politische oder auch nur kulturelle Autonomie einer bestimmten Bevölkerungsgruppe passte nicht in deren Bild. 1909/10 begann die neue Regierung sich bereits erheblich umfangreicher in lokale Fragen einzumischen, als dies zuvor unter dem gestürzten Sultan Abdul Hamid II. je der Fall gewesen war. Schon bald gingen angesichts dieser Entwicklungen viele Albaner auf Distanz zu den Jungtürken.

Die jungtürkische Revolution und die Wiedereinführung der Verfassung hatten bewirkt, dass der in den vorangegangenen Jahren immer blutiger geführte Bandenkrieg zwischen nationalistischen Bewegungen wie der probulgarischen IMORO (nach 1918 als IMRO bekannt), serbischen Četnici oder griechischen Andarti zunächst eingeschlafen war ${ }^{14}$. Bereits 1909 nahmen jedoch bewaffnete Aktionen wieder zu.

Die meisten albanischen Erhebungen gegen die osmanische Staatsmacht hatten vor 1908 überwiegend sozioökonomische Gründe und wurden häufig durch Steuererhöhungen ausgelöst. Politisch motivierte albanische Freischärlerbanden gingen zunächst nur aus wenigen südalbanischen revolutionären Komitees hervor $^{15}$. Nicht wenige von ihnen hatten sich von der jungtürkischen Bewegung die Erlaubnis für albanischsprachige Schulen erhofft - Hoffnungen, die sehr bald enttäuscht wurden. Als dann auch die Steuerlast schmerzlich erhöht wurde, brach in der Provinz Kosovo und in Nordalbanien Ende März 1910 ein Aufstand aus ${ }^{16}$. Getragen wurde er in erster Linie von konservativen Clanführern, die keinesfalls die Oberherrschaft des osmanischen Sultans an sich in Frage stellten, sich jedoch gegen die Politik der jungtürkischen Regierung stellten. Die Armee schlug den Aufstand blutig nieder und installierte eine Militärverwaltung. Sämtliche albanischsprachige Zeitungsredaktionen wurden geschlossen, tausende Männer in die Armee gepresst und nach Anatolien versetzt ${ }^{17}$. Diese Maßnahmen konnten jedoch nicht verhindern, dass sich die Unzufriedenheit weiter ausbreitete. Im Süden organisierten albanische Bandenführer wie Sali Butka ${ }^{18}$ oder Themistokli Gërmenji

Zur Bandentätigkeit siehe u.a.: Fikret Adanır, Die Makedonische Frage. Ihre Entstehung und Entwicklung bis 1908, Wiesbaden 1979 (= Frankfurter historische Abhandlungen, 20); Duncan M. Perry, The Politics of Terror. The Macedonian Liberation Movements 1893-1903, London 1988.

15 Peter Bartl, Die albanischen Muslime zur Zeit der nationalen Unabhängigkeitsbewegung (1878-1912), Wiesbaden 1968 (= Albanische Forschungen, 8), S. 148-152.

16 Zuzana Finger, Die albanische Nationsbildung. In: Peter Jordan [u.a.], Albanien. Geographie, Historische Anthropologie, Geschichte, Kultur, Postkommunistische Transformation, Frankfurt a.M. 2003, S. 135-149, hier S. 145.

17 Noel Malcolm, Kosovo. A Short History, London 2002, S. 241 f.

18 Sali Butka trat seit 1906 als Anführer albanischer Freischärler im Gebiet des heutigen Südalbanien in Erscheinung und bekämpfte die griechische Nationalbewegung im Epirus. 1916 unterstützten seine Kämpfer das Vordringen der österreichisch-ungarischen und bulgarischen Truppen. 1920 vertrat er als Delegierter die Stadt Korça auf dem Kongress 
nicht nur einen bewaffneten Kampf gegen die wieder aktiv werdenden griechischnationalistischen Freischärler, sondern wendeten sich nun außerdem gegen Einrichtungen des jungtürkischen Staates. Auch in der Armee rumorte es. Albanische Offiziere wehrten sich dagegen, mit ihren Einheiten in weit entfernte Unruheregionen des Reiches versetzt zu werden. Gleichzeitig begann sich die albanische Diaspora stärker zu vernetzen und die Bildung nationaler Geheimkomitees zu unterstützen.

Je mehr die jungtürkische Regierung ihren zentralistischen Kurs verstärkte und versuchte, durch ein höheres Steueraufkommen die Handlungsfähigkeit des verschuldeten Staates zu erhöhen, desto mehr schürte sie den Unmut ${ }^{19}$. Montenegro begann das Protestpotenzial der zahlreichen Flüchtlinge infolge des Aufstandes von 1910 auszunutzen und unterstützte nordalbanische Oppositionelle mit Waffen und Lebensmitteln. Weitere Steuererhöhungen und Rekrutenaushebungen riefen im Frühjahr 1911 erneut Aufstände hervor, diesmal überwiegend in den Regionen der Malësi und der Mirdita. Trotz des gegenseitigen Misstrauens näherten sich nun muslimische und katholische Aufständische einander an. Während mirditische Clanchefs eine »Provisorische albanische Regierung « mit dem Slogan »Albanien für die Albaner « ausriefen, distanzierten sich die konservativen kosovarischen Clanführer davon und forderten »nur« Autonomie $^{20}$.

$\mathrm{Zu}$ den wichtigsten Organisatoren des sich ausbreitenden Aufstands zählte der Publizist und Politiker Ismail Qemal Bey Vlora. Dieser entstammte einer reichen Großgrundbesitzerfamilie und hatte zunächst innerhalb des osmanischen Staatsdienstes Karriere gemacht. Als Anhänger der Reformbewegung und Verfechter eines dezentralen Staates hatte er sich 1908 als Abgeordneter der Stadt Berat ins neu eingerichtete osmanische Parlament wählen lassen. Zusammen mit anderen albanischen Politikern schloss er sich nun den Aufständischen an und war federführend an ihrem 13-Punkte-Programm beteiligt. Darin forderten die Aufständischen von der jungtürkischen Regierung u.a. die Achtung der religiösen und traditionellen Bräuche der lokalen albanischen Bevölkerung, die Anerkennung der Existenz einer albanischen Nation, die Einführung der albanischen Sprache in der lokalen Verwaltung und an den Gerichten bzw. des albanischen Sprachunterrichts an Schulen sowie die Ableistung des Militärdienstes in der jeweiligen Heimatprovinz der Rekruten ${ }^{21}$. Allerdings misslang der Versuch, den Aufstand auch auf Südalbanien auszudehnen. Dort kam es zwar im Sommer 1911 unabhängig von den Aufständen im Norden zu Unruhen, doch gelang es der Staatsmacht, die Situation durch Zugeständnisse frühzeitig wieder zu beruhigen. In Nordalbanien kamen die Waffen erst im Spätsommer zum Schweigen. Sultan Murat und sein Großwesir besuchten persönlich das kosovarische Prizren und sicherten den Clanchefs der Region neue Privilegien zu. Noch einmal beruhigte sich die Lage.

von Lushnjë. Siehe dazu: Marja Nikolaeva Todorova, Balkan Identities. Nation and Memory New York 2004, S. 108 f.

19 Romeo Gurakuqi, Kryengritja e Malësisë së Mbishkodrës e Vitit 1911, Shkodra 2002, S. 32-50.

20 Malcolm, Kosovo (wie Anm. 17), S. 244.

21 Bartl, Die albanischen Muslime (wie Anm. 15), S. 176 f., sowie Gurakuqi, Kryengritja (wie Anm. 19). S. 123-125. 


\section{Die Kriege 1911-1913 und die Geburt des albanischen Staates}

Angesichts der zunehmenden Rebellionen in verschiedenen Ecken des Osmanischen Reiches gegen die Politik der Jungtürken entschloss sich Italien, die Situation für die Durchsetzung seiner imperialistischen Expansionsziele zu nutzen, und erklärte dem Reich am 29. September 1911 den Krieg. Im November 1911 bildete sich aus dem radikalen Flügel der jungtürkischen Bewegung eine neue Partei heraus (»Freiheit und Einheit«). Wenige Wochen später wurde das Parlament aufgelöst. Bei den Neuwahlen im April 1912 sicherten sich die Radikalen die Mehrheit, während viele Autonomiebefürworter keine Sitze mehr erhielten. Dies betraf auch albanische Abgeordnete aus verschiedenen Regionen, die sich nun mit wichtigen Führungspersönlichkeiten der Aufstandsbewegungen aus den Jahren 1910 und 1911 zusammenschlossen.

Dies geschah in einer Situation, in der aufmerksamen Beobachtern klar sein musste, dass sich die benachbarten Balkanstaaten offenbar darauf vorbereiteten, gemeinsam die osmanische Herrschaft auf dem südlichen Balkan zu beenden. Hatten albanische Aufständische Hilfe in der Vergangenheit begrüßt, so wurde einer möglichen militärischen Intervention der Anrainerstaaten nun mit zunehmender Sorge entgegengesehen. Angesichts der vielfältigen Krisen des Staates war es mehr als ungewiss, ob das Osmanische Reich noch in der Lage war, eine Eroberung seiner Balkanprovinzen abzuwehren. Diese Angst trug wesentlich dazu bei, dass der im Mai 1912 beginnende Aufstand im Kosovo eine wesentlich breitere Basis besaß als die Aufstände der Jahre 1910/11 und von vornherein viel politischer motiviert war. Die zentralistische Politik der Jungtürken führte kosovarische Traditionalisten, Autonomiebefürworter und Reformpolitiker zusammen. In einem gemeinsamen Programm wurden u.a. die Einführung von Wahlkreisen nach ethnischen Kriterien, die Dezentralisierung der Verwaltung und die Einberufung einer Generalversammlung aller mehrheitlich von Albanern bewohnten Provinzen gefordert. Im Laufe weniger Wochen weitete sich der Aufstand auf die katholischen Bergstämme im äußersten Norden, das muslimische Mittelalbanien sowie die südostalbanische Region um Monastir aus. Ende Juni 1912 beschlossen die wichtigsten Führer der Aufstandsbewegung, dass die jungtürkische Regierung entweder zurücktreten und eine Nachfolgeregierung umfangreiche Reformen in den albanischen Provinzen durchführen oder den albanischen Gebieten vollständige Autonomie zugestehen solle. Damit ging es nicht mehr nur um die Bewahrung alter Privilegien der traditionellen Eliten, sondern um eine weitreichende Verwaltungs- und Kulturautonomie.

Am 17. Juli 1912 trat die Regierung zurück. Das Nachfolgekabinett suchte zwar Kontakt zu den Aufständischen, konnte aber nicht verhindern, dass diese bald darauf den Großteil der Provinz Kosovo kontrollierten. Am 5. August verkündete die neue Regierung die Auflösung des Parlaments und gab wenig später nahezu allen Forderungen der albanischen Rebellen nach. Daraufhin stellten die Aufständischen den Kampf ein. Ob die jungtürkische Regierung ihre Zugeständnisse wirklich erfüllt hätte, kann nur vermutet werden. Ihr blieb dafür keine Zeit mehr, denn dem Aufstand im Inneren folgte nun der befürchtete Angriff von außen.

Es ist nicht eindeutig geklärt, ob der Erfolg des albanischen Aufstandes unmittelbaren Einfluss auf die Entscheidung der Anrainerstaaten nahm, den offenen Konflikt mit dem Osmanischen Reich zu wagen. Historiker wie Krisztián Csaplár- 
Degovics konstatieren allerdings, dass die serbische Regierung in den Jahren 1910 bis 1912 mit wachsendem Misstrauen die wohlwollende Haltung ÖsterreichUngarns gegenüber den albanischen Aufstandsbewegungen verfolgte. Nachdem sich die Balkanstaaten in gegenseitigen »Freundschaftsverträgen « lose zusammengeschlossen hatten, mobilisierten sie nun ihre Truppen ${ }^{22}$.

Zunächst forderten die Regierungen Bulgariens, Griechenlands, Montenegros und Serbiens, allen christlichen Minderheiten im europäischen Reichsteil das Recht auf nationale Selbstbestimmung zuzubilligen. Mittelfristig hätte eine solche nationale Selbstbestimmung unweigerlich zum Anschluss solcher Territorien an die Balkanstaaten geführt. Deren Regierungen wird wahrscheinlich klar gewesen sein, dass die osmanische Regierung darauf nicht eingehen konnte. Da besonders Serbien und Bulgarien als sehr russophil galten, versuchte die österreichisch-ungarische Diplomatie eiligst zu intervenieren und plädierte für ein gemeinsames Auftreten aller Großmächte nach Vorbild früherer Krisengipfel, um nicht den Balkanstaaten die Initiative zu überlassen. Russland, aber auch Italien und das Deutsche Reich lehnten ein Eingreifen ab. Russland stellte sich vielmehr offen hinter die Forderungen der Balkanstaaten ${ }^{23}$. Als die osmanische Regierung diplomatisch auf Zeit zu spielen begann, brachen die Dämme. Montenegro arrangierte Grenzzwischenfälle und erklärte dem Osmanischen Reich am 8. Oktober 1912 den Krieg. Bis Ende des Monats folgten auch Serbien, Griechenland und Bulgarien. Es zeigte sich bald, dass die osmanischen Streitkräfte nicht in der Lage waren, den südosteuropäischen Reichsteil lange zu verteidigen. In einem raschen Tempo eroberten die Armeen der Balkanstaaten große Teile der osmanischen Territorien auf dem europäischen Kontinent.

Die Reaktionen unter den Albanern auf diese Entwicklung waren sehr unterschiedlich. Viele albanische Soldaten desertierten aus den kämpfenden osmanischen Einheiten. Gleichzeitig scharten sich Tausende von albanischen Kämpfern um frühere Aufstandsführer. Die Stammesmilizen im äußersten Norden leisteten hingegen lange Zeit keinen Widerstand gegen die vorrückenden Montenegriner und zogen sich in unwegsame Bergregionen zurück. Wenn Widerstand geleistet wurde, dann zur Verteidigung des eigenen Tales, nicht aus einem nationalen albanischen Identitätsgefühl heraus ${ }^{24}$. Nicht wenige nordalbanische Stammesführer oder Politiker hatten in den Jahren der Aufstände gute Kontakte zu serbisch-montenegrinischen Waffenschmugglern und gelegentlich auch Staatsvertretern unterhalten. Jetzt allerdings mussten sie miterleben, wie die serbischen Truppen und die sie unterstützenden irregulären serbischen Freischärler zu brutalen Vertreibungsaktionen gegenüber der albanischen Bevölkerung schritten.

In dieser Situation kamen verschiedene albanische Politiker zu der Überzeugung, dass nur ein eigenständiger albanischer Staat die Aufteilung der albanischen Gebiete würde verhindern können. So versuchte beispielsweise der südalbanische

22 Krisztián Csaplár-Degovics, Der Erste Balkankrieg und die Albaner. Ein Beitrag zur Geschichte der Unabhängigkeitsproklamation Albaniens (28. November 1912). In: SüdostForschungen, 67 (2008), S. 168-201, hier S. 169 f.

23 Die russische Regierung befürwortete dabei keineswegs einen Krieg der Balkanstaaten, sondern dachte vielmehr, diese enger an Russland binden zu können und im Gegenzug durch diplomatischen Druck die Hohe Pforte zu Zugeständnissen zu zwingen. Katrin Boeckh, Von den Balkankriegen zum Ersten Weltkrieg, München 1996 (= Südosteuropäische Arbeiten, 97), S. 23-25.

24 Csaplár-Degovics, Der Erste Balkankrieg (wie Anm. 22), S. 175. 
Parlamentsabgeordnete Sureya Bey Vlora vergeblich, in Mittelalbanien eine albanische Nationalversammlung zusammenzubringen und sich gleichzeitig Rückendeckung durch Österreich-Ungarn zu verschaffen. Es gelang ihm nicht, dafür die ausreichende Unterstützung der muslimischen Großgrundbesitzer Mittelalbaniens zu erhalten, die sich nach wie vor nicht gegen den osmanischen Sultan und Kalifen stellen wollten ${ }^{25}$. In ähnliche Richtung agierte ein anderer albanischer Wortführer, Ismail Qemali Bey Vlora. In Wien warb er für die Unterstützung eines autonomen Albanien und hoffte, dass die Großmächte einen solchen Kompromiss der vollständigen Auflösung der osmanischen Herrschaft auf dem Südbalkan vorziehen würden. Inwieweit er wirklich entsprechende Zusagen erhielt, ist umstritten. Jedenfalls kehrte er Mitte November eiligst in das schrumpfende, umkämpfte albanische Gebiet zurück. Inzwischen waren durch den raschen Vormarsch der serbischen und montenegrinischen Truppen viele albanische Nationalpolitiker entweder in Kriegsgefangenschaft geraten oder mit ihren Freischaren auf dem Rückzug in Richtung Vlora begriffen ${ }^{26}$. Der Historiker Oliver Jens Schmitt deutet es in dieser Situation dann auch als Verzweiflungstat, dass Ismail Qemali Flüchtlinge und einige Delegierte mancher süd- und mittelalbanischer Komitees in der noch unbesetzten Hafenstadt Vlora zu einem Nationalkongress zusammenführte und dort am 28. November 1912 einen albanischen Staat und die Bildung einer provisorischen Regierung ausrief ${ }^{27}$. In diesem Moment war diese Proklamation sicherlich alles andere als die artikulierte Meinung einer Mehrheit der Albaner. Ihre historische Bedeutung sollte vielmehr darin liegen, dass bei den Verhandlungen der Großmächte über die Zukunft Albaniens die italienische und österreichisch-ungarische Diplomatie wichtige Argumente erhielten, um die Gründung eines albanischen Staates als Kompromisslösung zwischen den divergierenden Interessen zu fordern.

Die Geschwindigkeit, mit der die Armeen der Balkanstaaten vorrückten, hatte die europäischen Mächte völlig überrascht. Zudem drohte sich der Konflikt zu einem »großen Konflikt « auszuweiten - war doch Österreich-Ungarn unter keinen Umständen bereit, ein stark vergrößertes russophiles Serbien zu dulden, schon gar nicht mit einem direkten Zugang zur Adria. Die russische Regierung wiederum konnte kaum anders, als der ihr zugeneigten serbischen Führung den Rücken zu stärken. Am 16. Dezember 1912 versammelten sich die Botschafter der Großmächte in London, um die offensichtliche Auflösung des Osmanischen Reiches unter eigene Regie zu bringen und einen Interessensausgleich auszuhandeln ${ }^{28}$.

Unterdessen ging der Krieg weiter und alle beteiligten Parteien nutzten die Gelegenheit, durch ethnische Vertreibungen Fakten für die spätere Aufteilung zu schaffen. Im Kosovo und in Mazedonien wurde im großen Stil die muslimische

Ekrem Bey Vlora, Lebenserinnerungen, Bd 1, München 1968, S. 253-257.

Fatmira Musaj, Isa Boletini (1864-1916), Tirana 1987, S. 163-167, und Csaplár-Degovics, Der Erste Balkankrieg (wie Anm. 22), S. 177-179.

Csaplár-Degovics, Der Erste Balkankrieg (wie Anm. 22), S. 189-193, und Schmitt, Die Albaner (wie Anm. 7), S. 149.

Karl Adam, Großbritanniens Balkandilemma. Die britische Balkanpolitik von der bosnischen Krise bis zu den Balkankriegen 1908-1913, Hamburg 2009 (= Schriftenreihe Studien zur Geschichtsforschung der Neuzeit, 61); Richard C. Hall, The Balkan Wars 1912-1913. Prelude to the First World War, London 2000; Franz-Josef Kos, Die politischen und wirtschaftlichen Interessen Österreich-Ungarns und Deutschlands in Südosteuropa 1912/13. Die Adriahafen-, die Saloniki- und die Kavallafrage, Wien 1996 (= Zur Kunde Südosteuropas, 2). 
Bevölkerung drangsaliert. Es kam zu zahlreichen Massakern, Dörfer wurden niedergebrannt und Moscheen zerstört. Auch die kleinen Gemeinden albanischer Katholiken sahen sich teilweise Zwangskonversionen ausgesetzt ${ }^{29}$. Dies trug wesentlich zu einer großen Fluchtbewegung bei, in deren Verlauf bis 1915 ungefähr 120000 Kosovaren ihre Heimat verließen, sei es in Richtung Istanbul und Kleinasien, sei es in Richtung albanische Adriaküste. Dieser Zustrom kosovarischer Flüchtlinge hatte nicht zuletzt in manchen Regionen des späteren albanischen Staates langfristige Folgen für die dortigen politischen Verhältnisse und die Identifikationsmuster der lokalen Bevölkerung.

Die Wochen verstrichen, in denen sich die Großmächte nicht einigen konnten, wobei sich nunmehr angesichts des griechischen Vormarsches in Richtung Vlora auch Italien verstärkt zu Wort meldete. Eine dauerhafte Präsenz Serbiens an der Adria war sowohl Italien als auch Österreich-Ungarn alles andere als recht. Aber auch eine griechische Inbesitznahme der Hafenstadt Vlora und der ihr vorgelagerten strategisch wichtigen Insel Sazan wurde von Rom als klare Bedrohung der eigenen Interessen gewertet ${ }^{30}$.

Währenddessen entstanden in Albanien gleich mehrere politische Herrschaftsbereiche. Von Vlora aus versuchte die provisorische Regierung, möglichst viel Terrain zu halten und dort eine notdürftige Verwaltung aufzubauen. Im Norden entschieden sich Anfang des Jahres 1913 die politischen Führer der Malësi- und der Mirdita-Region, nun doch mit Montenegro und Serbien zu kooperieren, um sich an die Spitze autonomer katholischer Fürstentümer setzen zu können. Als weiterer Akteur trat der bereits erwähnte Esat Pascha Toptani auf. Dieser war im Dezember 1912 vom osmanischen Oberkommando als Anführer einer Entsatzstreitmacht zur belagerten Stadt Shkodra geschickt worden. Als der dortige Kommandeur Riza Pascha die Stadt der provisorischen Regierung überantworten wollte, ließ Esat Pascha Toptani ihn kurzerhand ermorden. Wenig später zog er sich mit den verbliebenen osmanischen Truppen aus Shkodra zurück, was ihm wahrscheinlich das Wohlwollen Montenegros einbrachte. Gleichzeitig versicherte er sich des Rückhalts wichtiger Feudalherren in Mittelalbanien und knüpfte Kontakte zu den dortigen serbischen Besatzern.

Inzwischen gelang es den Großmächten, sich trotz divergierender Interessen noch einmal in den zentralen Streitpunkten auf Kompromisse zu einigen. Allerdings sollte gerade die albanische Frage die Beziehungen zwischen Österreich-Ungarn und Russland sowie Italien nachhaltig belasten. Zugleich hatte die Erfahrung der Großmächte, dass Akteure wie der montenegrinische König Nikola oder die serbische Regierung von Premierminister Nikola Pašić immer wieder versuchten, die Entscheidungen der Großmächte zu unterlaufen und oft erst unter massivem Druck nachgaben, auf viele Diplomaten prägend gewirkt. Vieles spricht dafür, dass die Julikrise 1914 ohne den Konflikt um die 1912/13 strittige Frage eines serbischen Adriazugangs an der albanischen Küste anders verlaufen wäre. Gerade mit Blick darauf, dass Serbien erst Ende 1913 nach wiederholten österreichisch-ungarischen Drohgebärden seine Militärpräsenz in Albanien beendete, stellt der Historiker Christopher Clark fest: »Dieses mühsame Katz-und-Maus-Spiel zwischen Wien

30 Massimo Borgogni, Tra Continuità e Incertezza. Italia e Albania (1914-1939). La strategia politico-militare dell'Italia in Albania fino all'Operazione »Olltre Mare Tirana«, Milano 2007, S. 15 f. 
und Belgrad erklärt nicht zuletzt, warum die österreichischen Entscheidungsträger allmählich das Vertrauen in die Wirkung üblicher diplomatischer Verfahren bei Interessenkonflikten mit Serbien verloren [...] Das Axiom, dass Serbien letztendlich nur die Sprache der Gewalt verstehe, gewann an Bedeutung ${ }^{31}$." Eine diplomatische Lösung strebte die österreichisch-ungarische Regierung im Sommer 1914 gegenüber Serbien nicht mehr an.

Bereits Ende 1912 hatten sich die Großmächte grundsätzlich auf die Schaffung eines albanischen Staatswesens verständigt. Jedoch bedeutete dieser Kompromiss, dass rund die Hälfte der albanischsprachigen Bevölkerung nicht Teil dieses Staates sein würde. Das Kosovo, die Städte Skopje und Tetovo sowie die Region Debar wurden Serbien zugesprochen. Andere überwiegend albanische Gebiete fielen an Montenegro und Griechenland. Eine internationale Kommission sollte die endgültigen Grenzen festlegen. Schließlich erkannten alle sechs europäischen Großmächte am 29. Juli 1913 die Unabhängigkeit Albaniens offiziell an und garantierten dessen Souveränität. Dies war der kleinste gemeinsame Nenner im Machtspiel um den westlichen Balkan. Österreich-Ungarn und Italien hofften dabei, in einem albanischen Staat entscheidenden Einfluss ausüben zu können. Allerdings glaubten viele Diplomaten von vornherein nicht an die Lebensfähigkeit dieses Staates. Ohnehin stand die garantierte Souveränität nur auf dem Papier. Wie beschlossen, überwachte vorerst eine siebenköpfige Kontrollkommission, bestehend aus jeweils einem Vertreter der sechs Großmächte und einem albanischen Delegierten, die Verwaltungsgeschäfte des neuen Staates. Auch der zukünftige Fürst des Landes wurde von den Großmächten ausgesucht. Über das, was dann konkret passieren sollte, bestanden jedoch allenfalls vage Vorstellungen.

Auf dem Gebiet des skizzierten albanischen Staates spitzten sich die Machtkämpfe derweil zu. Am 12. Oktober 1913 berief Esat Pascha, sozusagen als eigene Regierung, einen mittelalbanischen Senat $\operatorname{ein}^{32}$. Dieser setzte sich aus konservativen Großgrundbesitzern und muslimischen Geistlichen zusammen und wurde von der jungtürkischen Regierung in Istanbul unterstützt. Damit festigte Esat Pascha seine Position in der Frage, wer zukünftig in Albanien die führende Kraft sein solle, egal unter welchem Fürsten.

Unterdessen schlugen Rumänien und Österreich-Ungarn den jungen deutschen Offizier Wilhelm Prinz zu Wied für dieses Amt vor. Er war mit dem rumänischen Königshaus verwandt und schien als Protestant geeignet, eine neutrale Haltung gegenüber den albanischen Katholiken, Orthodoxen, Sunniten und Bektaşi einzunehmen. Darüber hinaus war er als deutscher Adliger unverdächtig, verlängerter Arm einer Großmacht zu sein, da das Deutsche Reich (bislang) kein übermäßiges Interesse an der Region gezeigt hatte. Aus der Perspektive der europäischen Mächte stellte er sich so als der ideale Kompromisskandidat dar. Wilhelm Prinz zu Wied war allerdings gänzlich unvorbereitet auf diese Aufgabe im »Hexenkessel« Albanien und besaß keinerlei diplomatische Erfahrung.

Derweil trat am 16. Oktober 1913 die Internationale Kontrollkommission in Durrës zusammen. Die Lage vor Ort war desaströs. Noch hielten serbische bzw. griechische Truppen den Osten und den Süden des Landes besetzt. Die ohnehin

31 Christopher Clark, Die Schlafwandler. Wie Europa in den Ersten Weltkrieg zog, München 2013, S. 372 und 375.

32 Koli Xoxi, Ismail Qemali, Tiranë 1983, S. 343. 
schwache Wirtschaft lag am Boden. Der Krieg hatte Zerstörung und Flüchtlingselend hinterlassen, während es besonders in Mittelalbanien angesichts der großen sozialen Not der bäuerlichen Bevölkerung gefährlich brodelte. Eine funktionierende Verwaltung existierte allenfalls auf kommunaler Ebene in wenigen Städten. Weder die konservativen Feudalherren Mittelalbaniens, die Stammesführer im äußersten Norden noch die liberal-bürgerlichen Politiker der Nationalbewegung waren wirklich bereit, Zugeständnisse zu machen und nach gemeinsamen Lösungen zu suchen. Die Internationale Kontrollkommission indes erkannte weder die provisorische Regierung noch Esat Paschas Senat an. Stattdessen zwang sie diese am 22. Januar 1914 zur Selbstauflösung ${ }^{33}$. Im Gegenzug wurden deren Vertreter bei der Neuverteilung der wichtigsten Posten berücksichtigt. Esat Pascha aber hielt an seinen Machtansprüchen fest. Als gewiefter Taktiker löste er zwar seinen »Senat« auf, ließ sich aber von der Kontrollkommission zum Anführer jener offiziellen Delegation bestimmen, die im Namen des albanischen Volkes dem Prinzen zu Wied im Februar 1914 die neue Fürstenkrone antrug. Es gelang Esat Pascha, die Delegation mit eigenen Anhängern zu besetzen. Dies versetzte ihn in die Lage, von vornherein starken Einfluss auf den unerfahrenen Fürsten zu nehmen. Dies fiel ihm umso leichter, da Wilhelm zu Wied, der die Landessprache nicht beherrschte, vom ersten Tag an von einheimischen Beratern abhängig war. Ohnehin bestand die Autorität Wilhelms nur im unmittelbaren Umfeld von Durrës ${ }^{34}$.

Nachdem mehrere osmanische Würdenträger dankend den Posten des Regierungschefs des neuen Staates abgelehnt hatten, wurde schließlich Turhan Pascha Përmeti dazu überredet. Dieser bereits 75-jährige ehemalige Diplomat war jedoch mit den Gegebenheiten in Albanien ebenso wenig vertraut wie sein junger Souverän Wilhelm. Der eigentlich starke Mann war Esat Pascha Toptani, der sich mit dem Innen- und dem Kriegsministerium zwei Schlüsselressorts sicherte und Sympathisanten aus den Reihen der mittelalbanischen Feudalherren mit Ämtern versorgte. Am 10. April 1914 verabschiedete die Internationalen Kontrollkommission eine von westeuropäischen Juristen und Diplomaten ausgearbeitete Verfassung. Dessen ungeachtet sahen die Großmächte Albanien aber auch weiterhin nicht als souveränen Staat $\mathrm{an}^{35}$.

\section{Der Beginn des Ersten Weltkrieges und der Zerfall des Fürstentums Albanien}

Vom ersten Tag an stand die albanische Regierung vor schier unlösbaren Problemen. Der Staatshaushalt basierte in erster Linie auf Krediten der Großmächte, die spätestens nach Beginn des Ersten Weltkrieges gestrichen wurden. In den Randreton 2003, S. 24 f. Zur kurzen Herrschaft des Fürsten siehe Hanns Christian Löhr, Die Gründung Albaniens (wie Anm. 3), darüber hinaus die Abhandlungen von Duncan Heaton-Armstrong, The Six Month Kingdom. Albania 1914, London 2005, und Fernando Salleo, Albania: un regno per sei mesi, Palermo 2000.

35 Robert Schwanke, 50 Jahre Verfassungs- und Verwaltungsleben in Albanien. In: Osteuropa-Recht, 9 (1963), S. 2. 
gionen des Landes besaßen weder die Internationale Kontrollkommission noch das Kabinett Permëti nennenswerten Einfluss. Mit Ausnahme einer kleinen Miliz und einiger Freiwilligenverbände aus Abenteurern und Söldnern existierten keine Streitkräfte ${ }^{36}$. Dies sollte sich umso gravierender auswirken, als Griechenland nicht bereit war, jene Gebiete des Epirus, die Albanien zugeschlagen worden waren, zu räumen. Stattdessen rief dort im Februar 1914 der ehemalige griechische Außenminister Georgios Christakis-Zografos mit geheimer Rückendeckung der griechischen Staatsführung eine »Provisorische Regierung des Nordepiros « aus ${ }^{37}$. Wenig später gab der Offizier Spyros Spyromilios im Bergland südlich von Vlora die Geburt der »Autonomen Republik Himara « bekannt ${ }^{38}$. Die Großmächte handelten, ohne sich mit der albanischen Regierung abzustimmen, mit Griechenland im Mai 1914 die Deklaration von Korfu aus. Darin wurde der griechisch-orthodoxen Bevölkerung des Nordepirus eine weitgehende Autonomie innerhalb Albaniens zugesichert. Dies beruhigte aber die Situation nur kurzzeitig. Bereits am 6. Juli 1914 besetzten griechisch-epirotische Milizen die südostalbanische Stadt Korça. Ungehindert gingen Freischärler repressiv gegen die lokale albanisch-muslimische Bevölkerung vor, was zu Massakern und Vertreibungsaktionen führte. Allein die Stadt Vlora sah sich bald mit rund 25000 Flüchtlingen konfrontiert ${ }^{39}$. Die albanische Regierung stand dem weitgehend machtlos gegenüber. Zunehmend beunruhigt war von dieser Situation auch Italien, das eine Besetzung von Vlora durch griechische Soldaten befürchtete. Die Epirusfrage blieb bis nach dem Ersten Weltkrieg einer der vielen Brennpunkte des südwestlichen Balkans ${ }^{40}$.

Ein viel größeres Problem entwickelte sich für den jungen albanischen Staat jedoch in Mittelalbanien. Dort verschärften sich die sozialen Gegensätze zwischen der verarmten Landbevölkerung und den Großgrundbesitzern. Der letztendliche Auslöser für die daraus folgenden Aufstände ist bis heute umstritten. Das Gebiet zählte zum Kerneinflussgebiet von Esat Pascha Toptani, jedoch ist unklar, welche Rolle er bei den Ereignissen spielte. Fest steht, dass die Aufstände im Juli begannen und sich sehr rasch ausbreiteten. Von den Großmächten, die sich mittlerweile gegenseitig bekriegten, war keine Hilfe mehr zu erwarten. Nunmehr gewannen die Gegner Esats Oberwasser und überzeugten Fürst zu Wied, diesen zu entlas$\operatorname{sen}^{41}$. Esat Pascha ging daraufhin nach Italien, dessen Rückhalt er sich in den vorangegangenen Monaten »erarbeitet $«$ hatte $^{42}$.

36 Erwin A. Schmidl, Im Land der Skipetearen. Die internationalen Friedensoperationen in Albanien 1913-1914. In: Österreichische Militärische Zeitschrift, 35 (1997), S. 436 f.

37 Basil Kondis, Greece and Albania, 1908-1914, Thessaloniki 1976 (= Institute for Balkan Studies, 167), S. 124 f., und Edith Pierpont Stickney, Southern Albania or Northern Epirus in European International Affairs, 1912-1923, Stanford, CA 1926, S. 42.

38 Nataša Gregorič Bon, Contested Spaces and Negotiated Identities in Dhërmi/Drimades of Himarë/Himara Area, Southern Albania, Diss., University of Nova Gorica 2008, S. 142-144, www.ung.si/ library/doktorati/interkulturni/3GregoricBon.pdf [letzter Zugriff: 6.1.2015].

39 Borgogni, Tra Continuità e Incertezza (wie Anm. 30), S. 19.

40 Siehe dazu George B. Leon, Greece and the Albanian Question at the Outbreak of the First World War, Thessaloniki 1970 (= Balkan Studies, 11), S. 61-80; Nicola Guy, The Albanian Question in British Policy and the Italian Intervention, August 1914-April 1915. In: Diplomacy \& Statscraft, 18 (2007), 1, S. 109-131.

41 Romeo Gruakuqi, Shqipëria 1911-1914, Tiranë 2012, S. 649-657, sowie Heaton-Armstrong, The Six Month Kingdom (wie Anm. 34), S. 96-107.

42 Kurzzeitig reiste Esat Pascha auch nach Athen, um die griechische Regierung davon zu überzeugen, zusammen mit Serbien in Albanien zu intervenieren und den Fürsten zu 
Esat Paschas Sturz konnte jedoch die Lage nicht beruhigen. Als schließlich die Rebellenverbände vor der Hauptstadt standen, gab Fürst zu Wied auf und verließ am 3. September 1914 das Land. Das albanische Fürstentum schien damit bereits wieder am Ende, bevor es überhaupt richtig mit Leben erfüllt worden war.

Die Rebellen richteten am 3. September in Durrës einen Senat und eine provisorische Regierung ein. Angesichts der eigenen Heterogenität zerstritten sie sich aber bald über politische Richtungsfragen und konnten nur notdürftig Teile Mittelalbaniens kontrollieren. Es fehlte ihnen die Durchsetzungskraft, um die sozialen Gegensätze zwischen Bauern und Feudalherren zu überbrücken, sodass bereits innerhalb weniger Wochen der Rückhalt der Aufständischen bröckelte. Im Norden sahen sich Politiker wie der Anführer der Mirditen, Prênk Bibë Doda, oder der Malësi, Ded Coku, mehr denn je als unabhängige Fürsten ihrer Stammesregionen und ignorierten die Putschregierung beflissentlich. Nichts anderes taten die griechischen Nationalisten der epirotischen Regierung. Angesichts des Kriegseintrittes des Osmanischen Reiches auf Seiten der Mittelmächte, ließen die Ententemächte Griechenland im Epirus gewähren und boten ihm sogar die dauerhafte Annexion Südalbaniens an, falls es seine Neutralität zu ihren Gunsten aufgeben sollte ${ }^{43}$. Dies wiederum lag nicht im Interesse der italienischen Außenpolitik. Bereits früh hatten die britische und russische Diplomatie damit begonnen, die Regierung in Rom zu umwerben, sich ihnen im Krieg gegen Österreich-Ungarn anzuschließen, wofür Italien die Annexion der begehrten albanischen Hafenstadt Vlora in Aussicht gestellt wurde ${ }^{44}$. Noch ging die Regierung in Rom darauf nicht ein, sah aber dieses Angebot quasi als Freibrief, sich dem griechischen Vordringen entgegenzustellen und sich die Kontrolle über die Seestraße von Otranto zu sichern. Mit dem Verweis auf die »anarchischen Zustände « und unter dem Vorwand, in einer »humanitären Intervention « das Flüchtlingselend in und um Vlora zu lindern, landeten Ende Oktober 1914 italienische Truppen auf der strategisch wichtigen Insel Sazan und später in der Hafenstadt Vlora ${ }^{45}$. Die Aktion wurde zwar als »vorübergehend « deklariert, doch orakelten politische Kreise in Rom offen über die Errichtung eines mittelalbanischen Fürstentums ${ }^{46}$. Nach und nach wurde die dortige militärische Präsenz ausgebaut ${ }^{47}$. Von großen Teilen der lokalen albanischen Bevölkerung wurden die Italiener zunächst begrüßt, da die italienische Landung zum Rückzug der griechischen Armee bis zur 1913 vereinbarten Südgrenze führte. Dies änderte sich, als später bekannt wurde, was Italien mit den Ententemächten hinsichtlich Albaniens ausgehandelt hatte. So ließ sich die Regierung von Premierminister Antonio Salandra im Londoner Abkommen vom 26. April 1915, das den Kriegseintritt Italiens auf Seiten der Entente besiegelte, unter anderem die spätere Annexion von Vlora absegnen.

Wied zu vertreiben; er wurde dort aber abgewiesen. Politisches Archiv des Auswärtigen Amtes (PA AA), R 4289, Telegramm des deutschen Gesandten in Athen, Quadt, vom 1. September 1914.

43 Owen Pearson, Albania in the Twentieth Century. A History, vol. 1: Albania and King Zog. Independence, Republic and Monarchy 1908-1939, New York 2004, S. 81-83.

44 Guy, The Albanian Question (wie Anm. 40), S. 115-117.

45 Borgogni, Tra Continuità e Incertezza (wie Anm. 30), S. 21 f.; Pearson, Albania in the Twentieth Century (wie Anm. 43), S. 82.

46 Guy, The Albanian Question (wie Anm. 40), S. 118-120.

47 Borgogni, Tra Continuità e Incertezza (wie Anm. 30), S. 24. 
Im Schatten dieser Ereignisse erschien mit Esat Pascha Toptani ein alter politischer Taktiker wieder auf der Bühne, während gleichzeitig mit Ahmet Muhtar Bey Zogolli-Mati ein neuer Mitspieler an Profil gewinnen sollte. Esat Pascha war nach seinem erzwungenen Exil zunächst von Italien nach Frankreich gegangen. Nach Beginn des Weltkrieges knüpfte er Kontakte zur serbischen Regierung von Nikola Pašić. Diese hatte kein Interesse an einem Machtvakuum in Albanien. Während Serbien im Norden zusammen mit Montenegro Krieg gegen Österreich-Ungarn führte, bedeuteten die 1913 erworbenen und nur oberflächlich integrierten Gebiete im Süden für Belgrad eine beständige Gefahrenquelle.

Seit September 1913 kam es zu gemeinsamen Operationen von albanischen Freischärlern und der IMORO gegen serbische Truppen ${ }^{48}$. Esat Pascha bot sich der Regierung Pašić in dieser Situation als »starker Mann « $\mathrm{an}^{49}$. Er versicherte sich der Unterstützung Serbiens und kehrte nach Albanien zurück. Dank serbischer Hilfe warb er in der Grenzstadt Debar einige tausend Bewaffnete an und konnte zeitweise auch einen Teil der bäuerlichen Aufstandsbewegung in Mittelalbanien für sich gewinnen. Innerhalb kurzer Zeit brachte Esat Pascha mit seiner Truppe die Gebiete rund um Durrës und Tirana unter seine Kontrolle. Er übernahm den Vorsitz der in Durrës sitzenden Regierung und rief sich selbst als neuen Staatschef Albaniens aus. Esat Pascha traute sich jedoch nicht, das sozialrevolutionäre Potenzial unter den mittelalbanischen Bauern zu nutzen, und stützte sich stattdessen erneut auf konservative Großgrundbesitzer.

Als »Staatschef« erklärte Esat Pascha den Mittelmächten offiziell den Krieg, was der internationalen Presse nicht mehr als eine kurze Zeitungsmeldung wert war. Die Mittelmächte erkannten ihn nie als Staatsoberhaupt Albaniens an. Entsprechend blieb er in der Rolle des Vasallen Serbiens gefangen, der dem Nachbarn in Mittelalbanien die Flanke »ruhig « zu halten hatte. Diese Rolle konnte er allerdings nur unzureichend ausfüllen ${ }^{50}$. Nach dem Kriegseintritt des Osmanischen Reiches intensivierte auch die jungtürkische Regierung wieder ihre Agitation gegenüber den albanischen Muslimen in Mittelalbanien und im Kosovo ${ }^{51}$. Die daraus hervorgehende sogenannte Union von Kruja drängte Esats Einfluss bis Ende 1914 Stück um Stück zurück. Dieser neuen Aufstandsbewegung näherte sich auch der junge ehrgeizige Anführer der mittelalbanischen Mati-Region, Ahmet Muhtar

48 PA AA, R 4847, Schreiben der deutschen Botschaft in Rom vom 17.1.1914; Haus-, Hofund Staatsarchiv Wien (HHStA), PA XIV 2 Albanien Durazzo 1914-1916, Telegramm von Löwenthal vom 13.4.1914, sowie PA I 820 Liasse Krieg 2 e, Politischer Bericht des k.u.k. Konsulats Valona (Vlora) vom 28.7.1914; Telegramm des k.u.k. Generalkonsuls in Skutari (Shkodra), August Ritter von Kral, vom 1.8.1914; Telegramm des k.u.k. Gesandten in Sofia, Adam Tarnowski, vom 25.8.1914, und Telegramm des k.u.k. Konsuls in Saloniki, von Kwiatkowski, vom 16.11.1914. Siehe auch Dimităr G. Gočev, Nazionalno-osvoboditelnenata borba v Makedonija 1913-1915, Sofija 1981, S. 123.

49 Andrej Mitrović, Srbija u Prvom svetskom ratu, Beograd 2004, S. 218-229; Dušan T. Bataković, Serbian Government and Essad Pasha Toptani, http://balkania.tripod.com/ resources/history/kosovo_chronicles/kc_part2e.html [letzter Zugriff: 6.1.2015].

50 Siehe dazu Shukri Rahimi, Marrëveshjet e Qeverisë Serbe me Esat Pashë-Toptanin gjatë viteve 1914-1915. In: Gjurmime Albanologjike - Seria e shkencave Historike 1976, Bd 6, S. 117-142.

51 HHStA, PA I 982 Liasse Krieg 42, Telegramm des k.u.k. Botschafters in Pera, Pallavicini, vom 26.1.1915; Telegramm des k.u.k. Konsuls in Skutari (Shkodra), Halla, am 29.1.1915, und Politischer Bericht des k.u.k. Botschafters in Pera, Pallavicini, vom 4.2.1915. 
Bey Zogolli, an. Er versuchte sich mit der serbischen Regierung zu arrangieren und sich gleichzeitig als neuer starker Mann Mittelalbaniens zu positionieren.

In den Wintermonaten versuchten sowohl die Mittelmächte als auch die Ententestaaten Bulgarien auf ihre Seite zu ziehen. Besonders die russische Diplomatie stellte der bulgarischen Regierung territoriale Kompensationen auf Kosten des serbischen Teils Mazedoniens in Aussicht, wofür Serbien als Entschädigung Teile Albaniens zugesprochen werden sollten. Ob das Kabinett Pašić, falls die bulgarische Regierung dieses Angebot angenommen hätte, auf diesen Tauschhandel eingegangen wäre, ist nicht sicher, doch mögen diese diplomatischen Gedankenspiele die serbische Regierung ermutigt haben, die eigene Präsenz in Albanien auszubauen. Als die Situation für Esat Pascha immer kritischer wurde, gab die serbische Führung, alle Warnungen ihrer alliierten Verbündeten ignorierend, im Juni 1915 rund 20000 Soldaten den Befehl, in Mittelalbanien einzumarschieren. Diese zerschlugen die Verbände der Union von Kruja und lieferten ihre Anführer an Esat Pascha aus, der sie exekutieren ließs ${ }^{52}$. Das Mati-Gebiet Zogollis blieb dabei verschont. Im Norden nutzte wiederum Montenegro die Gelegenheit, um seinerseits mit einer starken Interventionstruppe die Stadt Shkodra und deren Umgebung zu besetzen $^{53}$. Damit ging Montenegro zugleich gegen das Bestreben der österreichisch-ungarischen Diplomatie vor, die mittels ihres Konsulats in Shkodra führenden nordalbanischen Notabeln durch Subsidienzahlungen als mögliche Freischärlerführer für sich zu gewinnen trachtete ${ }^{54}$. Tatsächlich konnte Montenegro solche Pläne mit seinem Einmarsch kurzzeitig unterbinden. In den darauffolgenden Wochen spaltete der montenegrinische Einmarsch die dortigen albanischen Stämme. Während die Mirditen die Montenegriner unterstützten, sah sich die montenegrinische Interventionstruppe bald einem wachsenden Widerstand seitens der Malësi ausgesetzt $^{55}$. Das Unternehmen gestaltete sich für die montenegrinische Führung umso schwieriger, da sie es nicht mit ihren Verbündeten abgestimmt hatte und da-

52 HHStA, PA I 821 Liasse Krieg Serbien i-o, Politischer Bericht des k.u.k. Konsuls in Saloniki, Ernst von Kwiatkowski, vom 31.8.1915. Darin leitete dieser einen Bericht des albanischen Politikers Hasan Basri Bey Dukagjini über die Ereignisse in Mittelalbanien weiter.

53 Georgia Ioannidou-Bitsiadou, La situation politique en Serbie durant la premiere semestre de 1915. In: Proceedings of the Fifth Greek-Serbian Symposium, Thessaloniki 1987, S. 45-58.

54 HHStA, PA I 982 Liasse Krieg 42, Politischer Bericht des k.u.k. Konsuls in Skutari (Shkodra), Halla, vom 8.1.1915. Die österreichisch-ungarische Diplomatie hatte bereits seit Kriegsbeginn die Möglichkeit ins Auge gefasst, den katholischen Norden des Landes mittelfristig als Gegengewicht gegen die Kriegsgegner Montenegro und Serbien einsetzen zu können. Als sich im September 1914 eine wachsende Zahl albanischer Freiwilliger für das österreichisch-ungarische Heer beim k.u.k. Konsul in Shkodra meldeten, wies Außenminister Leopold Graf von Berchtold seine diplomatischen Vertreter in Albanien darauf hin, dass es nicht im Interesse der Habsburger Monarchie sei, die »waffentüchtigen Elemente Albaniens « gegenüber Serbien und Montenegro zu schwächen. HHStA, PA I 871 Liasse Krieg 6, Telegramm des k.u.k. Außenministers Graf Berchtold vom 23.9.1914 an den k.u.k. Generalkonsul Kral.

55 HHStA, PA XIV 2 Albanien Durazzo, Politischer Bericht der k.u.k. Gesandtschaft in Durazzo vom 29.8.1915, sowie PA I 820 Liasse Krieg Serbien 2 h, Politischer Bericht des k.u.k. Konsuls in Skutari, Halla, vom 19.10.1915. 
mit großen Unmut in Italien und Serbien hervorrief ${ }^{56}$. Die serbische Regierung erwog zeitweise, ihre Unterstützungszahlungen an Cetinje einzustellen ${ }^{57}$.

De facto war der albanische Staat nicht mehr existent. Zwar bestand das Fürstentum Albanien rein völkerrechtlich auf dem Papier fort, doch machtpolitisch war sein Staatsgebiet zwischen internen und externen Machtgruppen aufgeteilt. Der Süden war fest in griechischer Hand. In Zentralalbanien war ein fragiler Rumpfstaat unter serbischer Hegemonie entstanden, während Montenegro den äußersten Norden besetzt hielt. Nordalbanische Anführer wie Ahmet Zogolli oder Prênk Bibë Doda hatten ihre nahezu unabhängige Herrschaft in einer beständigen Pendelpolitik zwischen den lokalen Mächten stabilisieren können. Der Traum der kleinen albanischen Nationalbewegung wäre wahrscheinlich gescheitert gewesen, wäre in dieser Situation der Weltkrieg beendet worden. Es sollte allerdings anders kommen, da die Region im zweiten Kriegsjahr zum unmittelbaren Schlachtfeld der beiden Konfliktparteien wurde.

\section{Albanien als Kriegsgebiet 1915-1918}

Mit dem Ziel, eine direkte Landverbindung zum bedrängten Osmanischen Reich herzustellen, entschlossen sich die Mittelmächte im Sommer 1915 zu einer Großoffensive gegen Serbien. Mit großzügigen territorialen Versprechungen gelang es ihnen, die bulgarische Regierung für sich zu gewinnen. Im Oktober/November 1915 brach der serbische Widerstand zusammen. Schließlich drohten die Reste des serbischen Heeres von den gegnerischen Armeen im Kosovo eingekreist und vernichtet zu werden. Mitten im hereinbrechenden Winter entschloss sich die serbische Führung zum Rückzug aller noch verfügbaren Truppen durch das bergige Nordalbanien zur Adriaküste, ein Rückzug, den Tausende nicht überleben sollten. Sowohl die österreichisch-ungarische als auch die bulgarische Heeresführung gaben ihren Truppen den Befehl zur Verfolgung. Während bulgarische Truppen in Mittelalbanien auf Tirana vorstießen, drängte die österreichisch-ungarische Armee durch Nordalbanien in Richtung Adriaküste vor.

Dies veränderte die politische Situation in Albanien grundlegend. Viele Politiker und Notabeln sowie Clan- und Stammesführer stellten sich nun gegen Serbien und Montenegro. In einer öffentlichen Erklärung versicherten am 28. Januar 1916 mehrere wichtige nordalbanische Honoratioren der Donaumonarchie ihrer Unterstützung und begrüßten die österreichisch-ungarischen Soldaten als Befreier ${ }^{58}$. Mag dies in erster Linie pragmatisches Handeln lokaler Eliten gewesen sein, die selten mit äußeren Mächten gute Erfahrungen gemacht hatten, so dürfte dabei auch die Annahme mitgespielt haben, dass Österreich-Ungarn als »Schutzmacht« letztlich die günstigere Option war. Zu eindringlich waren die Erfahrungen mit dem brutalen Vorgehen während des Ersten Balkankrieges sowie der nachfolgenden Julius von Szilassy, vom 30.6.1915.

57 HHStA, PA I 820 Liasse Krieg Serbien 2 h, Politischer Bericht des k.u.k. Konsuls in Skutari, Halla, vom 25.6.1915.

58 Pearson, Albania in the Twentieth Century (wie Anm. 43), S. 96. 
Serbisierungspolitik im Kosovo und Mazedonien. Einige der albanischen Verbände beteiligten sich auch aktiv an der österreichisch-ungarischen Eroberung Montenegros, spielten aber auch beim weiteren österreichisch-ungarischen Vormarsch eine nicht unwichtige Rolle. Das k.u.k. Oberkommando forcierte die Aufstellung albanischer Kampfgruppen zusätzlich dadurch, dass es erfahrene Albanienreisende der Vorkriegszeit aussandte, die albanische Freischaren anwerben sollten ${ }^{59}$. Darüber hinaus unterstützten albanisch-kosovarische Nationalisten wie Hasan Bey Prishtina, Ferat Draga oder Azem Galica den Kampf gegen die zurückweichenden Serben mit Freiwilligenverbänden ${ }^{60}$. Das k.u.k. Außenministerium sah sich Ende Januar 1916 sogar veranlasst, die Armeeführung aufzufordern, beim Einsatz nordalbanischer Hilfstruppen zurückhaltender zu sein, um nicht muslimische oder orthodoxe Kräfte zu provozieren und diese so in die Arme Italiens oder Esat Paschas zu drängen ${ }^{61}$. Diese Befürchtungen erwiesen sich allerdings als unbegründet. Die albanische Bevölkerung zeigte sich überall gegenüber den einmarschierenden k.u.k. Truppen abwartend bis freundlich.

Auch Ahmet Zogolli ergriff nunmehr offen gegen Serbien Partei und bemühte sich, im Wettlauf gegen die Bulgaren mit seinen eigenen Kampfverbänden möglichst viele Städte Mittelalbaniens zu besetzen. Er versuchte, wenn auch vergebens, so viele Feudalherren und Notabeln wie möglich zu einem »Nationalkongress « zusammenzurufen, um unter seiner Federführung eine neue provisorische albanische Regierung zu bilden ${ }^{62}$. Wäre dies gelungen und wäre der schwache Wilhelm zu Wied zur Rückkehr aufgefordert worden, hätte sich Ahmet Zogolli als politische Schlüsselfigur in einem wiederbelebten albanischen Fürstentum etablieren können ${ }^{63}$. Doch dazu kam es nicht, weil Österreich-Ungarn und Bulgarien, selbst untereinander uneinig, in der Neugestaltung Albaniens die Initiative behalten wollten.

Unterdessen gelang es den Seestreitkräften der Entente die Reste des serbischen und montenegrinischen Heeres zu evakuieren. Unter großen logistischen Schwierigkeiten wurden die erschöpften Soldaten auf die Insel Korfu und in den französischen nordafrikanischen Stützpunkt Bizerta gebracht ${ }^{64}$. Esat Pascha zog sich mit seinen ihm verbliebenen Soldaten nach Durrës zurück, das von italienischen Truppen verteidigt wurde. Bereits Ende Februar 1916 zwangen ihn aber die vordringenden österreichisch-ungarischen Streitkräfte auch dort zum Abzug ${ }^{65}$. Er setzte sich zunächst nach Italien ab und ging im August 1916 nach Saloniki zum Hauptquartier der französisch-britischen Orientarmee. Esat Pascha nahm weiterhin für sich in Anspruch, rechtmäßiger Vertreter des albanischen Staates und gleichbe-

Christian Marchetti, Balkanexpedition. Die Kriegserfahrung der österreichischen Volkskunde - eine historisch-ethnographische Erkundung, Tübingen 2013, S. 205 f.

60 Ajet Haxhiu, Shota dhe Azem Galica, Tiranë 1976, S. 38 f.

61 HHStA, PA I 499 Liasse Krieg XLVII 2 b (1-19), Telegramm des k.u.k. Außenministeriums vom 27.1.1916 an den Vertreter des Ministeriums beim Armeeoberkommando, Douglas Graf v. Thurn und Valsássina.

62 Nicola Guy, The Birth of Albania. Ethnic Nationalism, the Great Powers of World War I and the Emergence of Albanian Independence, London 2012, S. 133.

63 Schmidt-Neke, Entstehung und Ausbau der Königsdiktatur (wie Anm. 10), S. 42.

64 Daniela Schanes, Serbien im Ersten Weltkrieg, Frankfurt a.M. 2011 (= Neue Forschungen zur ostmittel- und südosteuropäischen Geschichte, 3), S. 279 f.

65 Wolfgang Etschmann, Der Westbalkan im Ersten Weltkrieg. In: Militäroperationen und Partisanenkampf in Südosteuropa. Hrsg. von der Arbeitsgemeinschaft Truppendienst, Wien 2009, S. 150. 
rechtigter Verbündeter der Entente zu sein. Von Saloniki aus, wo er eine Exilregierung installierte, organisierte er im weiteren Verlauf des Krieges albanische Freiwilligenverbände, die im Rahmen der Orientarmee an der südostalbanischen Front kämpften. Diese hatte sich herausgebildet, nachdem der Vormarsch der bulgarischen und österreichisch-ungarischen Truppen in Südalbanien im April/Mai 1916 zum Erliegen gekommen war.

In den nachfolgenden zweieinhalb Jahren waren die albanischen Siedlungsgebiete in mehrere Besatzungszonen aufgeteilt. Dabei versuchte jede Besatzungsmacht, die albanische Bevölkerung auf die eigene Seite zu ziehen, was eine indirekte Stärkung der albanischen Nationalbewegung zur Folge hatte. Der größte Teil Albaniens blieb unter österreichisch-ungarischer Kontrolle, wofür eine Okkupationsverwaltung mit Sitz in Shkodra unter dem früheren Konsul August Ritter von Kral eingerichtet wurde. Die parallel existierenden zivilen und militärischen Verwaltungsstrukturen führten allerdings immer wieder zu Kompetenzstreitigkeiten ${ }^{66}$. Zudem konnte sich die österreichisch-ungarische Führung zu keiner eindeutigen Haltung darüber einigen, was aus Albanien werden sollte. Während sich der Chef des Armeeoberkommandos Conrad von Hötzendorf gegen einen eigenständigen albanischen Staat aussprach und besonders den Süden Bulgarien und Griechenland überlassen wollte, zog der k.u.k. Außenminister Stephan (István) Burián ein unabhängiges Albanien unter habsburgischem Einfluss in Betracht ${ }^{67}$.

Mit Blick auf die weitere Entwicklung des albanischen Staates sollte es von groBer Bedeutung werden, dass die k.u.k. Behörden in ihrem besetzten Landesteil nachhaltig den Ausbau der rückständigen Infrastruktur forcierten ${ }^{68}$. Dies diente nicht zuletzt einer besseren Versorgung der eigenen Truppen, erlaubte es aber auch, wichtige Arbeitsplätze für die albanische Bevölkerung zu schaffen, und förderte den Austausch zwischen Nord- und Mittelalbanien. Am 23. Januar 1917 erklärte August von Kral in einer öffentlichen Proklamation, dass die Donaumonarchie nur für die Dauer des Krieges Albanien besetzt halten und die Autonomie der Albaner bis dahin respektieren werde.

Ganz in der Tradition des früheren Kulturprotektorats der Habsburger Monarchie bemühte sich die österreichisch-ungarische Besatzungsverwaltung darüber hinaus um eine kulturelle Förderung des katholischen Nordens. Darin wurden auch wichtige Persönlichkeiten der albanischen Nationalbewegung einbezogen, nicht zuletzt Luigj Gurakuqi, der als »Direktor für Unterrichtswesen « die Aufgabe der Organisation des albanischen Bildungswesens übertragen bekam ${ }^{69}$. Tatsächlich sollten die Förderung eines albanischen Schulsystems und die zunehmende Mobilität durch den Bau von Straßen, Brücken und Eisenbahnen viel zur Belebung eines albanischen Zusammengehörigkeitsgefühls beitragen ${ }^{70}$. Hinzu kamen die

Wolfgang Etschmann und Erwin A. Schmidl, Albanien im Ersten Weltkrieg. In: Österreichische Militärische Zeitschrift, 35 (1997), S. 550.

67 HHStA, PA I 499 Liasse Krieg XLVII 2 b (1-19), Schriftwechsel zwischen Baron Burián und Conrad von Hötzendorf zwischen dem 31.12.1915 und 30.1.1916.

68 Zur Geschichte der k.u.k. Okkupationsverwaltung siehe die unveröffentlichte Dissertation von Helmut Schwanke, Zur Geschichte der österreichisch-ungarischen Militärverwaltung in Albanien (1916-1918), Wien 1982, sowie Pearson, Albania in the Twentieth Century (wie Anm. 43), S. 105 f.

69 Xhevat Repishti, Lufta për Mbrojtjen e Shkodrës në Vitet 1918-1920, Tiranë 1998, S. 35-37.

70 Gjergj Misha, Politische Kultur in Albanien. Identitäten und Loyalitäten bei den Alba- 
Bemühungen, das orale albanische Gewohnheitsrecht überregional zu kodifizieren und zu modifizieren, um eine einheitlichere Rechtsordnung zu fördern ${ }^{71}$. Die katholischen Stammesgebiete im äußersten Norden behielten ihren autonomen Status. In Mittelalbanien bemühte sich Österreich-Ungarn, die zentralen muslimischen Honoratioren einzubinden. Darunter befand sich auch Ahmet Zogolli, der im Range eines Oberst in die k.u.k. Armee aufgenommen wurde. Im Januar 1917 wurde er aber als Mitglied einer albanischen Delegation, die zur Thronbesteigung des neuen habsburgischen Kaisers Karl I. nach Wien reiste, aus Albanien entfernt und bis Kriegsende in Wien festgehalten.

Als zweite Besatzungsmacht trat, teilweise in Konkurrenz zu Österreich-Ungarn, dessen Verbündeter Bulgarien auf. Radikale nationalistische Kreise hatten bereits während der Balkankriege von einer Ausdehnung Bulgariens bis nach Mittelalbanien geträumt. Nach der Abreise des Fürsten zu Wied intensivierte die bulgarische Regierung ihre Bemühungen, ihren Einfluss in den albanischen Gebieten des westlichen Mazedonien und Ostalbaniens auszubauen. Gezielt versuchte sie, die Gründung lokaler bulgarophiler Komitees zu fördern, die eine Kandidatur des jungen bulgarischen Prinzen Kyrill für den albanischen Thron forcieren sollten ${ }^{72}$. Im östlichen Mittelalbanien bemühte sich die bulgarische Besatzungsmacht zeitweise, wenn auch nur mit geringem Erfolg, eine probulgarische, albanische Regierung unter dem Politiker Hasan Basri Bey Dukagjini zu etablieren ${ }^{73}$. Die bulgarische Führung schreckte später selbst vor einem Konflikt mit Österreich-Ungarn nicht zurück und beharrte darauf, dass sämtliche albanischen Gebiete, die, wie der bulgarische Zar Ferdinand I. es ausdrückte, mit »Strömen bulgarischen Blutes erobert worden seien «, zu behalten ${ }^{74}$. Allerdings mussten auf Druck Österreich-Ungarns die bulgarischen Truppen einen Teil des von ihnen Anfang 1916 besetzten mittelalbanischen Territoriums wieder räumen. Bulgarien weigerte sich jedoch, den Südosten des Kosovo mit den Städten Prizren und Prishtina wieder zu verlassen und gliederte ihn seiner mittlerweile errichteten Militärverwaltung im besetzten Vardar-Mazedonien an.

Anders als Österreich-Ungarn verfolgte Bulgarien zudem eine Besatzungspolitik, die allein darauf zielte, die wirtschaftlichen und militärischen Ressourcen der okkupierten albanischen Gebiete bestmöglich auszunutzen ${ }^{75}$. Als sich der Krieg viel länger hinzog als erhofft, starben in diesem ausgeplünderten Versorgungs-

nern. In: Politische Kultur in Südosteuropa. Identitäten, Loyalitäten, Solidaritäten. Hrsg. von Alois Mosser, Frankfurt a.M. 2006, S. 142.

71 Marchetti, Balkanexpedition (wie Anm. 59), S. 194-197.

72 HHStA, PA I 874 Liasse Krieg 6 h, Telegramm Hohenlohe, Berlin 31.1.1916; Telegramm Graf Thurn vom 28.1.1916, und Bericht des k.u.k. Botschafters in Konstantinopel János von Pallavicini Nr. 10 vom 1.2.1916; HHStA, KA 1916 Präs. 51-34/3, sowie Muin Çami, Shqipëria në Marrëdhëniet Ndërkombëtare (1914-1918), Tiranë 1987, S. 258-262.

73 Schmidt-Neke, Entstehung und Ausbau der Königsdiktatur in Albanien (wie Anm. 10), S. 41.

74 PA AA, R 5095, Politischer Bericht des deutschen Botschafters in Wien, Heinrich von Tschirschky, vom 15.2.1916. Siehe auch Genčo Kamburov, Fatalnata iluzija. Voennopolitičeski protivorečija i konflikti meždu Bălgarija i Centralnite Sili v Părvata Svetovna Vojna (1914-1918), Sofija 1999, S. 170-174.

75 Björn Opfer, Im Schatten des Krieges. Besatzung oder Anschluss - Befreiung oder Unterdrückung? Eine komparative Untersuchung über die bulgarische Herrschaft in Vardar-Makedonien 1915-1918 und 1941-1944, Münster 2005 (= Studien zur Geschichte, Kultur und Gesellschaft Südosteuropas, 3), S. 93-101. 
raum 1917/18 tausende Bewohner an Hunger. Materiell unterstützt von der deutschen Heeresleitung, begann auch die bulgarische Armee, unter der lokalen albanischen Bevölkerung rund 15000 Soldaten zu rekrutieren ${ }^{76}$. Eine Einbeziehung albanischer Eliten in die Besatzungsverwaltung fand hingegen ebenso wenig statt wie eine kulturelle Förderung. Stattdessen betrieben die bulgarischen Behörden besonders in den mazedonischen Territorien eine rücksichtslose Bulgarisierungspolitik, die gegenüber der albanisch-muslimischen Bevölkerung stark repressive Züge annahm ${ }^{77}$. Wer nicht bereit war, sich zu assimilieren, wurde von den bulgarischen Besatzern als Störfaktor im zukünftigen Großbulgarien angesehen. 1917 sank allerdings das Interesse der bulgarischen Führung an den albanischen Gebieten. Die albanischen Kampfverbände wurden aufgelöst und auch als Polizisten eingesetzte Albaner entwaffnet ${ }^{78}$. Zu diesem Zeitpunkt waren die meisten Albaner bereits hinsichtlich einer möglichen Zusammenarbeit mit Bulgarien desillusioniert und vereinzelt kam es auch zu Widerstand albanischer Freischärler gegen die bulgarische Besatzungsmacht ${ }^{79}$.

Eine zivilisatorische Mission ähnlich derjenigen der österreichisch-ungarischen Institutionen verfolgte jenseits der Front die französische Okkupationsmacht. Im Herbst 1915 war ein französisch-britisches Expeditionskorps in der griechischen Hafenstadt Saloniki gelandet. Bevor diese Streitmacht wirksam eingreifen konnte, war die serbische Armee bereits geschlagen und auf dem Rückzug nach Albanien. Trotzdem blieb sie unter dem Kommando des französischen Generals Maurice Sarrail als sogenannte Orientarmee in der Region. Obwohl der griechische Staat offiziell neutral war, besetzte die Orientarmee nach und nach größere Gebiete im Norden des Landes. Infolgedessen wurde die griechische Regierung im Sommer 1916 gezwungen, ihre Truppen aus dem Epirus abzuziehen ${ }^{80}$. An ihrer Stelle besetzten von Vlora aus italienische Truppen etappenweise den größten Teil dieser Region. Um eine Verbindung zum italienischen Verbündeten herzustellen, rückten Ende November 1916 französische Verbände in die Region Korça vor. Dort bestanden unklare politische Machtverhältnisse, da die seit Oktober 1914 bestehende griechische Verwaltung und Garnison im innenpolitischen griechischen Machtkampf (Royalisten versus Venizelisten) gespalten waren. General Sarrail befürchtete, dass das griechische Militär die Stadt räumen und den bulgarischen Truppen überlassen würde, die nur wenige Kilometer entfernt standen. Esat Pascha schlug Sarrail vor, seine albanische Exilregierung nach Korça zu verlegen, was dieser jedoch ablehnte. Das Risiko war zu groß, dass der in Südalbanien wenig populäre Esat Pascha in Korça mehr Schaden als Nutzen verursachen würde, weil seine Anwesenheit sowohl die örtlichen Griechen als auch lokale albanische Kräfte gegen sich aufbringen würde ${ }^{81}$. Die Behörden der Orientarmee suchten stattdessen die Zu-

76 Centralen Voenen Archiv Veliko Tărnovo (ZVA) F 40 op, 1 a. e. No. 126, S. 76; Dimităr Minčev, Učstie na naselenieto ot Makedonija v bălgarskata armija prez Părvata Svetovna Vojna 1914-1918 g., Sofija 1994, S. 116.

77 HHStA, PA I 976, Bericht Nr. 20.192 des Vertreters des k.u.k. Außenministeriums beim Armeeoberkommando in Baden vom 5.6.1917, und Politischer Bericht Nr. 18 des k.u.k. Konsuls in Skopje, Dr. Vrbanić, vom 18.10.1917.

78 HHStA, PA I 994 Liasse Krieg 47 h-k, Bericht des k.u.k. Militärgouvernements in Serbien vom 14.7.1918.

79 Shaban Braha, Idriz Seferi në lëvizjet kombëtare shqiptare, Tiranë 1981, S. $219-222$.

80 Etschmann, Der Westbalkan im Ersten Weltkrieg (wie Anm. 65), S. 160.

81 Pearson, Albania in the Twentieth Century (wie Anm. 43), S. $102 \mathrm{f}$. 
sammenarbeit mit einheimischen Vertretern der albanischen Nationalbewegung und beschränkten sich auf die Organisation des Etappenwesens zur Versorgung der nahegelegenen Front. Die Verwaltung von Korça überließen die Franzosen einem vierzehnköpfigen Verwaltungsrat, der paritätisch aus je sieben Vertretern der muslimischen und der griechisch-orthodoxen Bevölkerung gebildet wurde ${ }^{82}$. Als 15. Delegierter gehörten bis Mai 1917 der französische Oberst Henry Descoins und anschließend General Salle dem Verwaltungsrat an. $\mathrm{Zu}$ seinen Mitgliedern zählte auch der in Südalbanien bekannte Bandenführer Themistokli Gërmenji ${ }^{83}$.

Am 10. Dezember 1916 erklärte General Sarrail, allerdings ohne sich darüber ausreichend mit dem französischen Kabinett von Premierminister Aristide Briand abgestimmt zu haben, den Bezirk von Korça und einigen angrenzenden Gemeinden zu einer »autonomen Republik ${ }^{84}$. Die italienische Regierung protestierte gegen dieses französische Vorgehen, was aber das französische Oberkommando der Orientarmee ignorierte. So erhielt der Verwaltungsrat die Möglichkeit, unter der Leitung von Themistokli Gërmenji eigene Polizeiverbände aufzubauen ${ }^{85} .1917$ wurden sogar eigene Briefmarken und Geldscheine gedruckt. Gërmenji forcierte die Einrichtung einer wachsenden Zahl albanischsprachiger Elementarschulen, während der Unterricht in griechischer oder türkischer Sprache eingestellt wurde ${ }^{86}$.

Die autonome »Republik Korça« mit ihren etwa 130000 Einwohnern schien zu einer Keimzelle für ein neues, frankophiles Nachkriegsalbanien zu werden. Allerdings wurde der Gestaltungsspielraum der albanischen Verwaltung bereits ab Sommer 1917 wieder zurückgeschraubt. Die politischen Rahmenbedingungen änderten sich. Italien beharrte weiterhin auf der Vorherrschaft in der Region. Am 3. Juni 1917 proklamierte in der Stadt Gjirokastër der Kommandeur der italienischen Streitkräfte im besetzten Südalbanien, General Giacinto Ferrero, seinerseits ein unabhängiges Albanien unter italienischem Protektorat. Nicht zuletzt auf Drängen der italienischen Regierung, die weiterhin die vollständige Kontrolle im Besatzungsgebiet von eigenen Institutionen ausgeübt sehen wollte, kam es jedoch zu keinen weiterführenden Maßnahmen wie die Installierung einer eigenen albanischen Regierung ${ }^{87}$. Zwar stützte sich auch die italienische Besatzungspolitik auf bestehende kommunale Strukturen, nahm jedoch lange Zeit keine Albaner in wichtige Verwaltungsebenen auf. Erst Anfang 1917 integrierte die italienische Okkupa-

82 Stefan Popescu, Les Français et la République de Kortcha (1916-1920). In: P.U.F. Guerres mondiales et conflits contemporains, 213 (2004), 1, S. 81-83, sowie Muin Çami, Shqiptarët dhe Francezët në Korçë (1916-1920), Tiranë 1999.

83 Pearson, Albania in the Twentieth Century (wie Anm. 43), S. 103; Edwin E. Jacques, The Albanians. An Ethnic History from Prehistoric Times to the Present, Jefferson 1995, S. 363. Themistokli Gërmenji war nach dem Einmarsch der griechischen Armee in die Region Korça Ende Oktober 1914 zunächst ins bulgarische Exil geflüchtet. Ein Jahr später kehrte er zurück. Ebenso wie Sali Butka unterstützte er mit neuen Freischärlerverbänden die Mittelmächte. Gërmenji wechselte allerdings im Herbst 1916 auf die Seite der Franzosen und wurde von diesen als »starker Mann « in den Verwaltungsrat des autonomen Korça aufgenommen. Robert Elsie, Historical Dictionary of Albania, 2nd ed., Plymouth 2010, S. 162 f., sowie Maurice Sarrail, Mon Commandement en Orient, Mercuès 2012, S. 270.

84 Sarrail, Mon Commandement en Orient (wie Anm. 83), S. 271, sowie Guy, The Birth of Albania (wie Anm. 62), S. 135 f.

85 Çami, Shqiptarët dhe francezët në Korçe (wie Anm. 82), S. 177.

86 Guillaume Robert, L'Albanie et la France dans l'entre-deux-guerres: une relation privilégiée? In: Balkanologie, 2 (1998), 2, http://balkanologie.revues.org/index261.html [letzter Zugriff: 6.1.2015].

87 Mario Montanari, Le truppe italiane in Albania (1914-20 e 1939), Roma 1978, S. 110-112. 
tionsverwaltung einige albanische, italophile Notabeln. Die italienischen Besatzer konnten ihre Position gegenüber der lokalen Bevölkerung jedoch festigen, weil sie sich um eine gute Versorgungslage bemühten. Dies hob sie deutlich von den Zuständen im griechisch besetzten Südepirus ab. Nicht zuletzt infolge der großen wirtschaftlichen Schwierigkeiten Griechenlands herrschte dort eine überaus prekäre Lage ${ }^{88}$. Auf diese Weise gelang es der italienischen Besatzungsverwaltung, trotz der wenig ernst gemeinten Proklamation von Gjirokastër Druck auf die französische, aber auch griechische Albanienpolitik auszuüben. Als sich im innenpolitischen Machtkampf in Griechenland vollends die ententefreundliche Regierung von Premierminister Eleftherios Venizelos durchsetzte und das Land nunmehr offen an der Seite der Westmächte in den Krieg eintrat, musste auch wieder auf griechische Interessen in der albanischen Frage mehr Rücksicht genommen werden. Während erste griechische Truppen die Orientarmee zu verstärken begannen, wurde das französische Agieren gegenüber der autonomen Republik Korça zunehmend reservierter. Am 27. September 1917 zwang das Oberkommando der Orientarmee dem dortigen Verwaltungsrat eine Reihe von Veränderungen auf. Der nördliche Teil der Republik wurde dem unmittelbaren militärischen Etappengebiet zugeordnet und Esat Pascha unterstellt. An der Spitze des verbliebenen Rests stand fortan ein zwölfköpfiges Gremium, das zudem in seinen Handlungsspielräumen in den darauffolgenden Monaten Stück um Stück beschnitten wurde ${ }^{89}$. Diese Entwicklung gipfelte darin, dass der einflussreiche Politiker Themistokli Gërmenji Ende 1917 der Kollaboration mit den Mittelmächten bezichtigt, verhaftet und in Thessaloniki hingerichtet wurde ${ }^{90}$. Am 28. Februar 1918 wurde der autonome Status der Republik offiziell aufgehoben und die Gründung griechischer Schulen wieder erlaubt.

Letztlich war keine der vier Besatzungsmächte daran interessiert, sich eindeutig hinsichtlich einer Wiederbelebung des 1913/14 aus der Taufe gehobenen albanischen Staates zu positionieren. Jede verfolgte eigene Machtinteressen und musste Rücksicht auf die Interessen anderer Verbündeter nehmen. Nicht selten waren sich politische und militärische Führungsebenen in der Frage über die Zukunft Albaniens uneinig. Dessen ungeachtet versuchten alle vier Mächte zeitweise, möglichst viele kollaborationsbereite Albaner als militärisches Potenzial zu nutzen bzw. aufgrund der eingeschränkten eigenen personellen Möglichkeiten die lokalen Verwaltungsstrukturen in die Besatzungsherrschaft zu integrieren. Größere Autonomie gestanden lediglich in Teilen die österreichisch-ungarische sowie kurzzeitig die französische Okkupationsmacht zu. Es ist davon auszugehen, dass sich die albanischen Eliten in den jeweiligen Besatzungszonen auch wenige Illusionen machten. Die albanischen politischen Akteure nutzten pragmatisch und flexibel die jeweilige politisch-militärische Lage zur Verteidigung ihrer eigenen Stellung beziehungsweise zur Ausweitung ihres Einflusses. Zusammengearbeitet wurde mit jener Macht, die in den schwierigen Zeiten die meisten Vorteile bot. Österreicher, Italiener, Bulgaren und Franzosen boten bezahlte Posten in der Verwaltung Hornbostel, vom 11.4.1917.

89 Popescu, Les Français et la République de Kortcha (wie Anm. 82), S. 82.

90 Etienne Augris, Korçë dans la Grande Guerre: Le sud-est albanis sous administration française (1916-1918). In: Balkanologie, 4 (2000), 2, S. 7, http://balkanologie.revues.org/ index315.html [letzter Zugriff: 6.1.2015]. 
oder Lohn für Söldnerdienste und waren bereit, sich Wohlwollen mittels großzügiger Subsidien zu erkaufen. Dabei wurden allerdings so manche persönlichen Kontakte zwischen Vertretern der Besatzungsmacht und ehrgeizigen albanischen Politikern, Geschäftsleuten wie Bandenführern geschlossen, die auch nach Ende des Weltkrieges Bestand haben sollten ${ }^{91}$. Die Förderung eines albanischsprachigen Schul- und Pressewesens - zumindest unter österreichisch-ungarischer und französischer Besatzungsverwaltung - trug durchaus zur Verbreitung eines eigenen Nationalgefühls unter der albanischen Bevölkerung sowie zur Stärkung der kleinen Schicht bürgerlicher Kräfte bei. Gleichzeitig wurde der starke türkisch-osmanische Einfluss zurückgedrängt.

Das Schicksal der Albanien-Front wurde letztlich auf den großen Schlachtfeldern in Frankreich und Belgien entschieden. Dort gerieten die erschöpften Mittelmächte im Sommer 1918 endgültig in die Defensive. Ende September 1918 brach die mazedonische Front zusammen und Bulgarien schied aus dem Krieg aus. Als auch in Südalbanien die Entente angriff, zogen sich die österreichisch-ungarischen Truppen kampflos zurück. Die italienischen Truppen beeilten sich, noch vor den Serben und Franzosen große Teile Albaniens zu besetzen. Die abziehenden k.u.k. Einheiten sicherten sich ihren Rückzug durch das unwegsame Bergland der Mirditen mit Geldzahlungen und der Überlassung von Waffen ${ }^{92}$. So manch ein Clanund Bandenführer Nord- und Mittelalbaniens nutzte die Gelegenheit, sich und seine Gefolgsleute mit Beutewaffen auszurüsten, was den neuen Besatzern noch einige Schwierigkeiten bereiten sollte.

\section{Die »Albanische Frage in den Nachkriegsjahren}

Für Albanien hatten die Kriegsjahre weitreichende Folgen. Das Osmanische Reich, das bisher ein wichtiger Orientierungspunkt für die Loyalität der muslimischen Albaner gewesen war, schrumpfte zu einem unbedeutenden Kleinstaat zusammen und sollte sich 1923 zur säkularen Republik Türkei wandeln. Auch wenn Istanbul weiterhin ein wichtiges Zentrum für den albanischen Nationalismus blieb, trug das Ende des osmanischen Sultanats und Kalifats wesentlich dazu bei, dass sich die Muslime in Albanien mit »ihrem «Staat identifizierten. Der ambitionierte Ausbau der Infrastruktur, die Förderung eines albanischen Schulwesens und die Einbindung wichtiger albanischer Politiker in die Besatzungsverwaltung schufen Traditionslinien zu dem vor dem Krieg gegründeten albanischen Staat und ließen zumindest Teile des Landes ein wenig enger zusammenwachsen. Allerdings ging mit Ende des Krieges auch das Habsburger Reich unter und damit das wichtigste politische Gegengewicht zum serbischen und italienischen Nachbarn.

Die Zukunft Albaniens war somit im Herbst 1918 unklarer denn je. Das Land war wieder von ausländischen Truppen besetzt. Sieht man von Esat Pascha ab, der sich weiterhin als einziges legitimes Staatsoberhaupt betrachtete, allerdings von

91 Am deutlichsten zeigte sich dies bei Kontakten nach Italien, wovon Politiker wie Mufid Bey Libohova auch nach 1918 profitierten. Siehe dazu Schmidt-Neke, Entstehung und Ausbau der Königsdiktatur in Albanien (wie Anm. 10), S. 45 f.

92 Etschmann/Schmidl, Albanien im Ersten Weltkrieg (wie Anm. 66), S. 552 f. 
kaum jemandem als solches anerkannt wurde, existierte keine auch nur halbwegs glaubwürdige Institution, die in der Lage war, die albanischen Interessen zu vertreten. Ein Anknüpfen an das kurzlebige Fürstentum unter Wilhelm zu Wied war kaum möglich. Zu viele Absprachen und Versprechungen waren mittlerweile zwischen den Ententemächten und ihren Verbündeten getroffen worden.

Als sich Ende Oktober der Zerfall Österreich-Ungarns abzuzeichnen begann, beschlossen einige albanische Politiker, sich an die italienische Regierung zu wenden, um dort Schutz vor den zu erwartenden griechischen und serbischen Ansprüchen zu finden sowie Unterstützung für die Bildung einer provisorischen albanischen Regierung zu gewinnen. Eine solche vorläufige Regierung sollte, so stellte es sich die Gruppe albanischer Honoratioren und Politiker vor, auf der Friedenskonferenz der Siegermächte die Ansprüche der Albaner inklusive jener im Kosovo und des Südepirus verteidigen ${ }^{93}$. Mit dem Makel behaftet, von vornherein als verlängerter Arm Italiens angesehen zu werden, konstituierte sich schließlich am 25. Dezember 1918 in Durrës ein »Nationalrat«. Dieser berief eine provisorische Regierung unter Turhan Pascha Përmeti ein. Ähnlich wie 1914 als Regierungschef unter Fürst zu Wied war der mittlerweile nahezu 80-jährige Exdiplomat als leicht $\mathrm{zu}$ lenkender Kompromisskandidat der mittelalbanischen Feudaleliten vorgesehen. Die illusionäre Hoffnung, dass Italien sich bei den Verhandlungen für ein unabhängiges, ungeteiltes Albanien einsetzen werde, wird sich kaum jemand gemacht haben, hatte doch zuvor die sowjetische Regierung den Inhalt des Londoner Abkommens vom 26. April 1915 veröffentlicht. Es zeigte sich auch schnell, dass es für die italienische Besatzungsmacht gar nicht in Frage kam, das eingeführte Kriegsrecht wieder einzuschränken. Ende Juli 1919 verständigten sich die Regierungen in Rom und Athen sogar darüber, dass Nord- und Südepirus griechisch werden und aus dem Rest ein albanischer Rumpfstaat unter italienischem Protektorat gebildet werden sollte. Derartig vorgeführt, hatte die Delegation der provisorischen Durrës-Regierung wenig Chancen, sich auf der Pariser Friedenskonferenz 1919/20 Gehör zu verschaffen ${ }^{94}$. Damit standen die Durrës-Delegierten allerdings nicht allein da. Auch Esat Pascha war zu den Friedensverhandlungen nach Paris gereist. Da jedoch den Siegermächten nicht entgangen war, dass er in Albanien faktisch keinerlei Einfluss mehr besaß, wurde auch er kurzerhand ignoriert. Eine dritte Delegation traf aus Istanbul ein und repräsentierte unter Leitung des osmanischen Beamten Sulejman Bey Delvina die starke albanische Diaspora am Bosporus. Als vierte Gruppe trat eine kosovarische Delegation unter Hasan Bey Prishtina auf.

Besonders Großbritannien und Frankreich sprachen sich dafür aus, die Albanien-Thematik im Zusammenhang mit der Adria-Frage zu behandeln. Angesichts der Auflösung des Habsburger Reiches entwickelte sich die Neuordnung der dalmatischen Küste zu einem kontroversen Machtkampf zwischen dem neuen, am 1. Dezember 1918 gegründeten Staat der Serben, Kroaten und Slowenen (S.H.S.Staat) und Italien. Die beiden Westmächte wollten daher jenen Staat, der den Kürzeren ziehen würde, mit albanischen Territorien entschädigen. Auch Griechenland,

93 Mufid Bey Libohova, Politika ime ndë Shqiperi 1916-1920, Gjirokastër 1921 (Reprint Tiranë 2004), S. 2-10.

94 Schmidt-Neke, Entstehung und Ausbau der Königsdiktatur in Albanien (wie Anm. 10), S. $44-48$. 
so die französischen und britischen Vorstellungen, sollte auf Kosten Albaniens erweitert werden.

Angesichts dieser Situation formierte sich 1919 zunehmend lokaler Widerstand. Die Bereitschaft einer wachsenden Zahl der untereinander rivalisierenden Klientelverbände wuchs, sich in einer gemeinsamen Abwehrfront zusammenzufinden. Zugute kam den albanischen Kräften, dass Griechenland sich 1919 in Kleinasien in einen neuen Krieg verstrickte. Italien wurde durch innenpolitische Spannungen erschüttert und konzentrierte sich außenpolitisch auf den Fiume-Konflikt. Letzteres beschäftigte zwangsläufig auch den S.H.S.-Staat, der darüber hinaus im Grenzstreit mit Österreich stand. Die Belgrader Regierung pochte zwar weiterhin auf ihre Ansprüche hinsichtlich des Kosovo und der Debar-Region, engagierte sich aber ansonsten zunehmend weniger in der albanischen Frage. Angesichts der festgefahrenen Verhandlungen war es schließlich US-Präsident Woodrow Wilson, der in den Friedensverhandlungen forderte, Albanien nun doch aus der Adria-Thematik herauszulösen.

Die Gelegenheit war somit für die albanische Nationalbewegung günstig, als es am 21. Januar 1920 in der Stadt Lushnjë zu einem Treffen von Delegierten zahlreicher albanischer Interessengruppen kam. Dieser Kongress bildete ein wesentlich größeres Spektrum innenpolitischer Kräfte ab als die Regierung in Durrës. Unter Vorsitz von Sulejman Bey Delvina, der als Istanbuler Diaspora-Albaner nicht in die verschiedenen inneralbanischen Rivalitätskämpfe involviert war, wurde eine eigene provisorische Regierung ins Leben gerufen. Wenig später siedelte diese nach Tirana um, begann Freiwillige zu rekrutieren und den Druck auf die Durrës-Regierung zu erhöhen. Deren Einfluss war längst auf wenige Stadtgemeinden zusammengeschrumpft. Daher beschlossen die wichtigsten Vertreter der Durrës-Regierung am 22. Februar, sich lieber dem Delvina-Kabinett in Tirana anzuschließen. Als am 12. März die französischen Besatzungstruppen zunächst Shkodra und im Mai die Region Korça räumten und Frankreich sich damit aus dem albanischen Streitfall weitgehend herauszog, konnte die Delvina-Regierung ihren Einfluss auch nach Norden und Süden ausdehnen.

Auch die italienische Regierung, die innenpolitische Schwierigkeiten hatte, das teure militärische Engagement in Albanien zu rechtfertigen, konnte sich nicht mehr zu einem energischen Vorgehen durchringen ${ }^{95}$. Als weitere Siegermacht des Weltkrieges entschloss sich wenig später Griechenland zu einer Verständigung mit der Regierung in Tirana. Am 15. Mai 1920 einigten sich beide Seiten bei Verhandlungen auf eine Grenzziehung, die sich weitgehend an jener von 1913 orientierte. Damit fiel ein weiteres wichtiges Argument zur Rechtfertigung der italienischen Präsenz in Albanien zusammen. Ein Vordringen des griechischen Konkurrenten in Richtung Vlora war vorerst ausgeschlossen. Nicht zuletzt angesichts einer wachsenden innenpolitischen Krise entschied sich die italienische Regierung schließlich dafür, Ende Juli 1920 ebenfalls direkte Verhandlungen mit der Delvina-Regierung aufzunehmen. Am 2. August kam es zur Einigung, wonach Italien den Abzug seiner Streitkräfte mit Ausnahme der Insel Sazan garantierte. Wenig später verließen die letzten italienischen Besatzungssoldaten das Land.

Während Frankreich, Griechenland und Italien sich vorerst aus Albanien herauszuziehen begannen, versuchte Esat Pascha noch ein letztes Mal, seine ehrgei- 
zigen Ansprüche in Albanien durchzusetzen ${ }^{96}$. Wie bereits 1915 versicherte Esat Pascha sich erneut serbischer Unterstützung und rekrutierte bewaffnete Kampfverbände. Anfang Juni 1920 begannen seine Anhänger mit Aufständen. Am 13. Juni 1920 wurde jedoch Esat Pascha in Paris von dem albanischen Studenten und späteren Politiker Avni Rustemi erschossen. Es dauerte dann auch nicht lange, bis die Aufstandsherde wieder erloschen.

Ungeklärt blieb das Verhältnis zwischen der neuen albanischen Regierung und dem S.H.S.-Staat. Problematisch war vor allem die immer noch offene Frage, ob Albanien Anspruch auf das mehrheitlich von Albanern bewohnte Kosovo erheben oder sich mit den Grenzen von 1913 zufrieden geben würde. Zeitweilig setzte sich die Regierung in Belgrad während der Pariser Friedensverhandlungen auch für eine Aufteilung Albaniens ein, wobei sie selbst die früheren Annexionsziele Montenegros, das mittlerweile im S.H.S.-Staat aufgegangen war, übernahm ${ }^{97}$.

Die Kosovo-Frage war auch unter den politischen Kräften des Lushnjë-Kongresses umstritten. Die Regierung Delvina hielt sich dazu 1920 zunächst bedeckt. Es wurde jedoch immer deutlicher, dass die Regierung in Tirana kaum diplomatische Unterstützung der Großmächte finden würde und natürlich auch militärisch nicht die geringste Chance gegen die Streitkräfte des großen Nachbarn gehabt hätte ${ }^{98}$. Dessen ungeachtet versuchten die radikalen Kräfte im Kosovo im Sommer 1920 durch einen Aufstand ein Eingreifen Albaniens zu provozieren. Allerdings schlugen die weit überlegenen jugoslawischen Streitkräfte die Aufstandsbewegung in kurzer Zeit blutig nieder. In der Folge flüchteten zehntausende Kosovaren nach Albanien, was die dortigen politischen und sozioökonomischen Probleme zusätzlich verschärfte. Am 14. November 1920 brach die Delvina-Regierung auseinander. Das nachfolgende Kabinett versuchte notgedrungen, nach außen eine Entspannungspolitik zu verfolgen, in der das Kosovo keinen Platz haben konnte. Dadurch gelang es immerhin, dass am 17. Dezember 1920 mit britischer Befürwortung Albanien in den Völkerbund aufgenommen und damit international gegenüber dem S.H.S.-Staat gestärkt wurde ${ }^{99}$. Auch wenn die Kosovo-Frage weiterhin ein schwieriger Konfliktpunkt blieb, war die Souveränität Albaniens fortan gegenüber seinem östlichen Nachbarn gesichert. Zementiert wurde dies am 9. November 1921, als auf einer Botschafter-Konferenz die Siegermächte Albanien international anerkannten. Damit endeten vorerst die über ein Jahrzehnt andauernden kriegerischen Auseinandersetzungen um die Kontrolle dieser Region. Auch wenn es noch lange dauern sollte, bis Albanien tatsächlich eine funktionierende Staatlichkeit entwickeln konnte, war es doch nach den überstandenen Krisenjahren nun zum festen Bestandteil der europäischen Staatengemeinschaft geworden.

Albanien profitierte maßgeblich davon, dass sich die internationale Lage im Vergleich zur Vorkriegszeit grundlegend gewandelt hatte. Das Osmanische und das Habsburger Reich existierten nicht mehr. Italien und Griechenland waren mit anderen Konflikten bzw. gravierenden innenpolitischen Problemen beschäftigt. Serbien mutierte zum jugoslawischen Staat, der nun auch den größten Teil der dal-

Bataković, Serbian Government and Essad Pasha Toptani (wie Anm. 49).

Andrej Mitrović, Jugoslavija na Konferenciji 1919-1920, Beograd 1969, S. 169-176.

Austin, Greater Albania (wie Anm. 8), S. 237.

Die Erdölkonzessionen der britischen Anglo-Persian-Oil-Company in Albanien dürften hier maßgeblichen Einfluss ausgeübt haben. Schmidt-Neke, Entstehung und Ausbau der Königsdiktatur in Albanien (wie Anm. 10), S. 80. 
matischen Küste mit mehreren Adriahäfen beinhaltete und zunächst die Integration der zahlreichen neuen Gebiete bewältigen musste. Albanien verlor dabei erheblich an strategischer Bedeutung. Erst in den 1930er Jahren, als der italienische Faschismus zu einer aggressiven Imperialpolitik überging, rückte Albanien als Schnittstelle zwischen Italien, Jugoslawien und Griechenland wieder stärker ins Rampenlicht der internationalen Politik. Nach den Wirren der Anfangsjahre trug diese Entwicklung zusätzlich dazu bei, dass die gesellschaftlichen Eliten des jungen albanischen Staates ein beständiges Bedrohungsgefühl gegenüber sämtlichen Nachbarn entwickelten. Dieses Erbe wirkt, wenn auch abgeschwächt, bis in die Gegenwart fort ${ }^{100}$.

\begin{abstract}
The Albanian national movement was still quite young and heterogeneous when international conflicts lead to the foundation of the Albanian state in 1912/13. Located by the strategically important Strait of Otranto, it came into existence as a compromise and under the protection of the Great Powers in a time when the Osman Empire was collapsing and the South-eastern European States were practising an aggressive policy of expansion. Only a few months later World War I broke out and affected the region severely. Consequently, it took another ten years for the Albanian state to take permanent shape within the changed order of postwar Europe. At this point, however, the political self-concept of Albania had altered pertinently due to constant foreign intervention and occupation by opposing war parties. Some of these influences continue to affect Albania to the present day.
\end{abstract}

100 Pandeli Pani, Albanischer Nationalismus - eine Gefahr für die Region? In: Deutsche Welle vom 11.7.2013, www.dw.de/albanischer-nationalismus-eine-gefahr-f\%C3\%BCr-dieregion/a-16936236?maca=de-newsletter_de_suedostfokus-4930-html-newsletter [letzter Zugriff am 6.1.2015], und Thomas Fuster, Albanien verteilt Pässe. In: Neue Zürcher Zeitung vom 6.7.2013, www.nzz.ch/aktuell/international/reportagen-und-analysen/albanienverteilt-paesse-1.18111768 [letzter Zugriff: 6.1.2015]. 